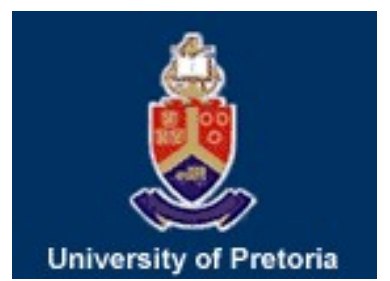

University of Pretoria

Department of Economics Working Paper Series

Spillover of Sentiment in the European Union: Evidence from Time- and Frequency-Domains

Vasilios Plakandaras

Democritus University of Thrace

Aviral Kumar Tiwari

Montpellier Business School

Rangan Gupta

University of Pretoria

Working Paper: 2019-09

February 2019

Department of Economics

University of Pretoria

0002, Pretoria

South Africa

Tel: +27 124202413 


\title{
Spillover of Sentiment in the European Union: Evidence from Time- and Frequency-Domains
}

\author{
Vasilios Plakandaras*, Aviral Kumar Tiwari* and Rangan Gupta ${ }^{* * *}$ \\ * Department of Economics, Democritus University of Thrace, Greece \\ Email: vplakand@econ.duth.gr \\ ${ }^{* *}$ Center for Energy and Sustainable Development (CESD), Montpellier Business \\ School, Montpellier, France. \\ Email: a.tiwari@montpellier-bs.com \\ ${ }^{* * *}$ Department of Economics, University of Pretoria, South Africa. \\ Email: rangan.gupta@up.ac.za
}

\begin{abstract}
The issue of economic integration of the economies consisting the European Union across its various leaps of expansion throughout the years has been brought back to light during the recent sovereign crisis of the southern economies of the Union, that lead to the necessity of large bailout programs. In this paper we depart from the typical approach in the field and examine economic synchronization through the lenses of economic sentiment spillovers based on the economic confidence index for 14 European economies. In doing so, we analyze sentiment spillovers both in time- and in the frequency-domains in order to reveal the dissemination of the perception of economic agents about the future economic climate throughout the EU. Our empirical findings support the segregation of the Union in the core European countries and the southern economies and highlight the role of the Germany as the dominant economy setting the pace for the Union after 2008. Interestingly, large economies as Netherlands and Austria appear to be neutral, not because of an isolation from the region, but due to changing roles in transmitting and accepting expectations about the economic environment.
\end{abstract}

Keywords: Sentiment, Spillover, Time- and Frequency-Domains, European Union.

JEL Codes: C32 


\section{Introduction}

The European Union (EU) integration has undoubtably been one of the most significant political and economic events of the $20^{\text {th }}$ century. In the years following the creation of the common market and the monetary union in the region, a popular research issue has been (and still ongoing) the synchronization effect in the economies of the countrymembers of the EU.

The main approach in studying the economic integration of the EU is the identification of a synchronisation in the business cycles between the economies that constitute the Union. On the theoretical side, the advocates of the endogenous business-cycle theory (see among others Frankel and Rose, 1997) argue that the synchronization would occur by reducing transaction costs, tariffs and quotas, leading to increased trading relationships. Increased trade linkages generate both demand- and supply-side spillovers across countries that can lead to highly correlated business cycles. Krugman (1993) goes a step further by stating that the specialization of economies in sectors of production where they have comparative advantages would lead to a reallocation of capital and eventually to business $\square$ cycle synchronization.

In contrast, the opponents of synchronization argue that sector-specific shocks transmitted through the increased trade linkages may facilitate increased specialization of production across countries, which in turn will lead to less synchronized business cycles (Baxter and Kouparitsas, 2005). On the practical (applied) side, the empirical evidence studies the GDP or a detrended version of it to support a synchronization effect between members of the EU, varying from traditional econometric (Artis et al., 2011) to more advanced methodologies such as the complex networks (Papadimitriou et al., 2016). A different approach is to use multivariate models including a variety of variables targeting the GDP (Antonakakis and Tondl, 2014).

In this paper, we advance from the two main approaches that pursue the existence of causal linkages directly in the evolution of the GDP of EU countries and address the problem of synchronization indirectly; as a problem of spillovers between economies. Given the intense trade relations between the EU countries, the existence of significant spillovers between economies is prima facie evidence of economic integration and commonality. Moreover, we depart from the examination of GDP and examine the 
common evolution of the Economic Sentiment Index (ESI). The ESI is an aggregate index from surveys across countries on businesses and households and report the economic sentiment in the economic environment, aiming to capture the expectations for the phase of the business cycle. Thus, we expect to unveil characteristics that may be hidden in an extremely aggregated index as the GDP.

Another innovation is the use of both a time- and a frequency-bands decomposition of the ESI indices in order to detect both time-varying and time-horizons (short-, medium, and long-runs) spillover effects. In doing so, we utilize the spillover methodology proposed by Diebold and Yilmaz (DY, 2012) for the time examination and the Barunik and Krehlik (BK, 2018) index for the frequency domain spillover analysis. The DY method is based on a VAR model and enables us to quantify the contribution of each economy as a net transmitter or a net receiver of economic sentiment, revealing the direction and the dominating economies in the EU region. In parallel, the frequency domain spillover index enables us to decompose the contribution of at different frequencies and thus observe the effect of spillovers at different time (investment) horizons as opposed to the time-varying DY method. In this way, we draw inferences on the necessary time that a market shock disperses in the region.

While, numerous studies (see Bathia and Berdin (2013) and Balcilar et al., () for detailed reviews) have investigated the effects of (investor) sentiment on financial markets (and the aggregate macroeconomy), with few studies having looked at the propagation of sentiment across international financial markets (see for example, Verma and Soydemir (2006); Bathia et al. (2016) for literature reviews in this regard). However, barring the work of Tiwari et al., (2018), who analyzed causality of sentiments across the US, Latin America, the Eurozone, Japan and Asia (excluding Japan), the extent to which (investor) sentiment is affected by the prevailing sentiment levels across countries (or regions) have not been investigated for any countries (or regions). Given that the sentiments are the reflection of individual's behaviour, spillover of sentiments across major countries and or regions remains an important question. This is more so, since sentiments are believed to lead financial markets and macroeconomic variables (see, Benhabib et al., (2016) for a thorough exposition). Note that, if sentiments across economies are interrelated, as the study of Tiwari et al., (2018) indicate, then even if there is no change in sentiment at the domestic level, a particular 
economy will end up witnessing the negative or positive sentiment impact through linkages that exist in a modern globalized world. Moreover, if domestic sentiments does improve or worsens, then sentiment feedbacks are likely to prolong the favorable or adverse effects on the domestic economy. Clearly then, policymakers needs to be aware of this, as the strength and nature of spillovers will determine the corresponding design of appropriate policies to either counteract the impact of negative sentiment spillover, or leave the policies unchanged to not to affect the positive influence of improvements in sentiments.

In light of the importance of the analysis of sentiment spillover, this is, to the best of our knowledge, the first paper to analyze spillover of sentiments across major EU economies. In the process we extend the regional investor sentiment analysis of Tiwari et al., (2018) by considering spillover of not only aggregate economic sentiment, but also its sectoral (industrial (business climate), services, consumer, retail trade, and construction) components, and that too in both time and frequency-domains. Sectorspecific analysis help us identify the sectors that drive the overall sentiment spillover, and would help in better design of sector-oriented policies in the wake of weaker sentiments. The rest of the paper is organized as follows: Section 2 presents the methodology, while Section 3 discusses the data and the results. Finally, Section 4 concludes.

\section{Methodological Issues and Data}

This section is divided in two parts; the first part discusses the time-domain spillover approach of Diebold and Yilmaz (2012) while the second presents the frequency domain spillover approach of Baruník and Křehlík (2018).

\subsection{DY spillover index approach}

The DY methodological framework is based on a generalized vector autoregressive process in which a forecast error variance decomposition (FEVD) is utilized to estimate connectedness and magnitude in the time domain. The starting point of the DY approach is a VAR process from which a forecast error variance decomposition is computed. Thus, we describe the n-variate process $x_{t}=\left(x_{t, 1}, \ldots, x_{t, n}\right)$ by structural $\operatorname{VAR}(\mathrm{p})$ at $t=1, \ldots, T$ as 


$$
X_{t} \Phi(L) x_{t}+\epsilon_{t}
$$

where $X_{t}$ represents a vector of $n \times 1$ endogenous variables, $\Phi(L)=\sum_{h} \Phi_{h} L^{h}$ is then $\times n$ p-th order lag-polynomial and $\epsilon_{t}$ is white-noise with possibly non-diagonal covariance matrix $\Sigma$. Assuming covariance stationarity, the VAR process has the following $\mathrm{MA}(\infty)$ representation:

$$
x_{t}=\Psi(L) \epsilon_{t}=\sum_{i=1}^{\infty} \Psi_{i} \epsilon_{t-1}+\epsilon_{t}
$$

where $\Psi(L)$ is an $n \times n$ infinite lag polynomial matrix of coefficients that can be calculated recursively. Pesaran and Shin (1998) show that the generalized forecast error variance decomposition (GFEVD) of a variable can be grouped into components attributable to shocks to the different variables in the system for a given forecast horizon $\mathrm{H}$ can be computed as:

$$
\Theta_{i j}(H)=\frac{\sigma_{j j}^{-1} \sum_{h=0}^{H}\left(\left(\Psi_{h} \Sigma\right)_{i j}\right)^{2}}{\sum_{h=0}^{H}\left(\Psi_{h} \Sigma \Psi_{h}^{\prime}\right)_{i i}}
$$

where $\Psi_{h}$ is a $n \times n$ matrix of coefficients corresponding to lag $h$, and $\sigma_{j j}=(\Sigma)_{j j}$, with $\Theta_{i j}(H)$ denoting the contribution of the $j^{\text {th }}$ variable of the system to the variance of forecast error of variable $i^{\text {th }}$ at the forecast horizon $H$. In the generalized VAR process of GFEVDs, by definition, given that own- and cross-variable variance contributions do not necessarily add up to one (i.e. within columns), we standardize the effect attributable to each variable as

$$
\tilde{\theta}_{i j}(H)=\frac{\Theta_{i j}(H)}{\sum_{j=1}^{n} \Theta_{i j}(H)},
$$

$$
\text { Where } \sum_{j=1}^{n} \Theta_{i j}(H)=1 \text { and } \sum_{i, j=1}^{n} \Theta_{i j}(H)=N
$$

the equation above, $\tilde{\theta}_{i j}(H)$ provides estimates of the pairwise connectedness from $j^{\text {th }}$ variable to $i^{\text {th }}$ variable at horizon $\mathrm{H}$ in the time domain. The degree of connectedness among the variables of a system can be ascertained with the aid of the above defined variance contribution. 


\subsection{The dynamic time- and frequency-domain spillover frameworks}

While the DY approach evaluates connectedness in the time domain, with little or no reference to the connectedness in the frequency domain. Following the idea of DewBecker and Giglio (2016), BK proposes a frequency response function that can be obtained as the Fourier transform of the coefficients $\Psi_{h}$, with $i=\sqrt{ }-1$ and defined as:

$$
\Psi\left(e^{-i h \omega}\right)=\sum_{h=0}^{\infty} e^{-i h \omega} \Psi_{h},
$$

where $\omega$ implies the frequency. Subsequent to the above, the power spectrum, $S_{X}(\omega)$, shows the distribution of $\mathrm{X}_{\mathrm{t}}$ over the frequency components $\omega$, and it is expressed as:

$$
S_{X}(\omega)=\sum_{h=0}^{\infty} E\left(X_{t} X_{t-h}\right) e^{-i h \omega}=\Psi\left(e^{-i h \omega}\right) \Sigma \Psi\left(e^{-i h \omega}\right)
$$

BK argue that the general variance decompositions in the frequency domain can be derived using the frequency response functions from the spectral representation. Essentially, the generalized forecast error variance decompositions at a particular frequency $\omega$ is computed using the expression:

$$
(\Theta(\omega))_{i j}=\frac{\sigma_{j j}^{-1} \sum_{h=0}^{\infty}\left(\Psi\left(e^{-i h \omega}\right) \Sigma\right)^{2}{ }_{i j}}{\sum_{h=0}^{\infty}\left(\Psi\left(e^{-i h \omega}\right) \Sigma \Psi\left(e^{-i h \omega}\right)\right)_{i t}},
$$

where $(\Theta(\omega))_{i j}$ is the portion of the spectrum of the $i^{t h}$ variable at a given frequency $\omega$ that can be attributed to shocks in the $j^{\text {th }}$ variable. It should be noted that from the expression above, forecast horizon $\mathrm{H}$ has no meaningful role to play.

Normalizing the frequency domain analysis, we have:

$$
\begin{gathered}
(\tilde{\Theta}(\omega))_{i j}=\frac{(\Theta(\omega))_{i j}}{\sum_{j=1}^{n}(\Theta(\omega))_{i j}}, \\
\text { where } \sum_{j=1}^{n}(\Theta(\omega))_{i j}=1 \text { and } \sum_{i, j=1}^{n}(\Theta(\omega))_{i j}=N .
\end{gathered}
$$

Hence, $(\tilde{\Theta}(\omega))_{i j}$ measures pairwise connectedness from $j$ to $i$ at a given frequency 
$\omega$ and thus can be interpreted as a within-frequency causality indicator. On the flipside, $\tilde{\theta}_{i j}(H)$ indicates the pairwise connectedness from $j$ to $i$ at a particular horizon $\mathrm{H}$, so it is considered as an indicator of the strength of causality exclusively in the time domain. In this line of reasoning, when DY quantify the connectedness relationships using $\tilde{\theta}_{i j}(H)$, they focus on the information aggregated through frequencies, while the possible heterogeneous frequency responses to shocks are entirely ignored.

In economic and financial analysis, it is important to assess the short-, medium-, or long-term connectedness relationships as focusing on causal interactions at a single frequency would ignore market adjustments that can occur at various horizons. Accounting for this feature in applications of connectedness relationships, the concept of frequency bands is essential. The cumulative connectedness at a random frequency band $c=(a, b)$ is obtained as:

$$
\left(\tilde{\Theta}_{c}\right)_{i j}=\int_{a}^{b}(\tilde{\Theta}(\omega))_{i j} c \omega
$$

and allows us to define a variety of connectedness measures in the frequency domain. The overall connectedness within the frequency band $c$ is then obtained as

$$
D^{c}=\frac{\sum_{i=1, i \neq j}^{n}\left(\widetilde{\Theta}_{c}\right)_{i j}}{\sum_{i j}\left(\widetilde{\Theta}_{c}\right)_{i j}}=1-\frac{\sum_{i=1}^{n}\left(\widetilde{\Theta}_{c}\right)_{i i}}{\sum_{i j}\left(\widetilde{\Theta}_{c}\right)_{i j}}
$$

The last phase of our estimation is to identify the direction of spillovers using the framework of BK. At the frequency band $c$, the contribution to the variance of the forecast error of variable $i$ by all other variables $(i \neq j)$ is called Within From connectedness and is computed as:

$$
D_{i, F r o m}^{c}=\sum_{j=1, i \neq j}^{n}\left(\tilde{\Theta}_{c}\right)_{i, j}
$$

In a similar vein, the contribution of variables $i$ to the forecast error variances of all other variables is called Within TO connectedness which at the frequency band $c$ is computed as:

$$
D_{i, T O}^{c}=\sum_{j=1, i \neq j}^{n}\left(\tilde{\Theta}_{c}\right)_{j, i}
$$


Having described the expressions for connectedness measures at both directions, one can also compute the net connectedness of frequency band $c$ such as $D_{i, N e t}^{c}=D_{i, T O}^{c}-D_{j, F r o m}^{c}$ for which the positive coefficient of $D_{i, N e t}^{c}$ indicates that variable $i$ transmits more information than it receives from all other variables in the system and vice-versa. Thus, the net pairwise connectedness between $i$ and $j$ can be calculated as:

$$
D_{i j}^{c}=\left(\tilde{\Theta}_{c}\right)_{j, i}-\left(\tilde{\Theta}_{c}\right)_{i, j}
$$

Finally, BK show that the contribution of the frequency band $\mathrm{c}$ to the entire system connectedness can be obtained using

$$
\widetilde{D}^{C}=D^{C} \cdot \Gamma(c)
$$

where $\Gamma(c)$ is the spectral weight, defined as $\sum_{i, j=1,}^{n}=\frac{\left(\widetilde{\Theta}_{c}\right)_{i j}}{\sum_{i, j=1}^{n}(\widetilde{\theta})_{i j}}=\frac{\sum_{i, j=1}^{n}\left(\widetilde{\Theta}_{c}\right)_{i j}}{n}$, which represents the contribution of the frequency band $\mathrm{c}$ to the entire system. They also note that the sum of all frequency connectedness measures should be over disjointed intervals is equal to the original total connectedness measure proposed by DY.

\subsection{The Data}

In order to analyze the spillover effects of economic confidence indicator between the EU countries, we use the monthly dataset provided by the European Commission for 14 European countries ${ }^{1}$. The dataset spans the period January, 1990 - March, 2018 and it is provided in an aggregated form as an overall economic confidence index, and in five component indices: an Industrial confidence indicator (40\%), a Services confidence indicator (30\%), a Consumer confidence indicator (20\%), a Retail trade confidence indicator $(5 \%)$ and a Construction confidence indicator $(5 \%)$. The weights used in the construction of the ESI are reported in parenthesis. All values are the result of survey polls conducted monthly within each economy. The descriptive statistics of

\footnotetext{
${ }^{1}$ More specifically the dataset covers Belgium, Denmark, Germany, Greece, Spain, France, Italy, Luxembourg, Netherlands, Austria, Portugal, Finland, Sweden and the UK. It can be accessed at https://ec.europa.eu/info/business-economy-euro/indicators-statistics/economic-databases/businessand-consumer-surveys/download-business-and-consumer-survey-data/time-series en\#economicsentiment-indicator-esi.
} 
the dataset are reported in Table 1.

\begin{tabular}{c|r|r|r|r|c}
\hline \hline & Table 1: ESI Descriptive Statistics & & \\
\hline Country & Mean & $\begin{array}{c}\text { Standard } \\
\text { Deviation }\end{array}$ & Kurtosis & Skewness & $\begin{array}{c}\text { Jarque-Bera } \\
\text { normality } \\
\text { test }\end{array}$ \\
\hline Belgium & 99.88 & 9.79 & 3.25 & -0.67 & $31.91^{*}$ \\
Denmark & 99.07 & 10.05 & 2.50 & -0.85 & $9.88^{*}$ \\
Germany & 101.09 & 9.63 & 3.43 & -0.82 & $49.48^{*}$ \\
Greece & 100.89 & 9.44 & 3.20 & -0.85 & $49.41^{*}$ \\
Spain & 100.78 & 9.66 & 3.35 & -0.98 & $62.46^{*}$ \\
France & 100.53 & 10.01 & 1.55 & -0.39 & 13.61 \\
Italy & 100.82 & 9.89 & 2.94 & -0.55 & $20.90^{*}$ \\
Luxembourg & 101.36 & 9.77 & 2.52 & -0.55 & $9.74^{*}$ \\
Netherlands & 100.42 & 9.43 & 3.84 & -0.73 & $48.72^{*}$ \\
Austria & 100.76 & 10.08 & 3.13 & -0.34 & $8.35^{*}$ \\
Portugal & 101.80 & 10.71 & 2.99 & -0.55 & $19.60^{*}$ \\
Finland & 100.59 & 9.49 & 2.97 & -0.38 & $18.61^{*}$ \\
Sweden & 100.37 & 10.20 & 2.99 & -0.62 & $24.52^{*}$ \\
UK & 101.59 & 10.37 & 4.08 & -0.69 & $51.93^{*}$ \\
\hline \hline
\end{tabular}

Note: Rejection of the null hypothesis about normality at the $5 \%$ level of significance is marked with an asterisk. The sample spans the period from January 1985- June 2017.

As we observe from the descriptive statistics, the ESI for all countries exhibit similar statistical characteristics. All indices are left-skewed, they all exhibit similar kurtosis to a normal distribution around 3, while none is actually a normal distribution, according to the JB test. Thus, by construction, all indices are very close to a normal distribution with a mean value around 100, allowing the asymptotical use of our decomposition schemes.

\section{Empirical results}

We start our analysis from the DY methodology for studying spillovers between countries. We base our analysis on a VAR (2) model with sentiment indices of 14 countries, where the lag order is determined according to the Akaike Information Criterion (AIC). A 100-period ahead forecasting horizon ${ }^{2}(\mathrm{H})$ for variance decomposition is used to construct the connectedness table (see Table 2), while we use a rolling window of 60 observations for the time-varying dynamic analysis (close to $20 \%$ of sample size). The rows of the Table report the source of sentiment transmission,

\footnotetext{
${ }^{2}$ The choice of forecasting horizon is based on suggestions of BK.
} 
while columns report the target economy. The total connectedness of the DY method is $47.14 \%$, suggesting a high level of economic integration between the EU economies. This similar economic climate is determined by the close proximity, the intense trade and the economic relations between the EU countries, especially after the creation of the Eurozone. We return to this issue later in the paper.

On a country level, according to the highest values of Table 2, Belgium receives and transmits to/from France (11.90\%), Denmark, Germany and Greece are bounded with the Netherlands $(2.91 \%, 10.34 \%$ and $1,68 \%)$, while Spain has a close link to France (7.09\%). Italy receives from Spain (5.97\%), Luxemburg from the Netherlands $(3.72 \%)$, the Netherlands and Austria from Germany (8.06\% and 7.74\%), Portugal is affected by the Netherlands (3.64\%), Finland receives from Sweden (2.99\%), Sweden from Austria (4.43\%) and the U.K. from Denmark (3.75\%). The spatial orientation seems important in the economic interlinkages between economies. The countries in the center of the Eurozone (Germany, France, Belgium, Netherlands, Austria and Luxemburg) affect mutually their level of sentiment related to economic activity and the expectations about the business cycle evolution, while the same is observed between the countries of the European south (Italy, Spain and Portugal). As expected, Sweden and Finland are closely linked, but the respective percentages are low, something that is also apparent in the U.K. Thus, while Scandinavian countries and the U.K. have close trade relationships with the EU, the economic sentiment (future expectations regarding the economic evolution) seem independent. The respective results for the 5 sub-indices are reported in Tables A1 to A5 in the Appendix of the paper, with the strongest connectedness observed for the services sector and followed closely by the consumer, building and industrial sectors, with least overall possibility of sentiment spillover observed under the retail trade sector. ${ }^{3}$ In sum, the overall spillover result is driven by the services, consumption and building sectors.

\footnotetext{
${ }^{3}$ Note the number of countries across the sectors are not always the same due to data availability and hence, makes uniform comparison a bit difficult.
} 


\begin{tabular}{|c|c|c|c|c|c|c|c|c|c|c|c|c|c|c|c|}
\hline & Belgium & Denmark & Germany & Greece & Spain & France & Italy & Luxemburg & Netherlands & Austria & Portugal & Finland & Sweden & UK & FROM \\
\hline Belgium & 37.12 & 2.89 & 9.01 & 0.79 & 5.84 & 10.36 & 4.86 & 3.67 & 6.99 & 7.02 & 2.55 & 2.20 & 3.46 & 3.24 & 4.49 \\
\hline Denmark & 4.59 & 59.47 & 4.03 & 1.01 & 2.87 & 5.10 & 2.05 & 2.02 & 4.21 & 3.81 & 2.88 & 1.76 & 2.45 & 3.75 & 2.90 \\
\hline Germany & 9.43 & 1.54 & 39.92 & 0.90 & 6.47 & 8.00 & 5.58 & 1.94 & 8.06 & 7.74 & 3.82 & 0.97 & 2.83 & 2.80 & 4.29 \\
\hline Greece & 2.73 & 0.85 & 3.00 & 76.48 & 3.02 & 1.89 & 0.77 & 0.82 & 2.67 & 2.04 & 1.50 & 0.40 & 1.18 & 2.66 & 1.68 \\
\hline Spain & 5.77 & 1.07 & 5.70 & 0.58 & 59.54 & 5.59 & 5.97 & 1.41 & 3.27 & 2.47 & 3.53 & 1.50 & 1.41 & 2.21 & 2.89 \\
\hline France & 11.90 & 2.12 & 7.71 & 0.62 & 7.09 & 38.82 & 4.63 & 2.39 & 6.80 & 5.21 & 3.18 & 2.82 & 4.02 & 2.68 & 4.37 \\
\hline Italy & 7.00 & 1.89 & 7.54 & 0.46 & 6.66 & 5.32 & 48.42 & 3.12 & 3.76 & 3.86 & 3.61 & 3.26 & 3.61 & 1.49 & 3.68 \\
\hline Luxemburg & 5.72 & 0.81 & 4.70 & 0.54 & 2.28 & 3.51 & 3.15 & 67.27 & 3.61 & 3.38 & 0.48 & 1.06 & 2.80 & 0.69 & 2.34 \\
\hline Netherlands & 10.55 & 2.91 & 10.34 & 1.68 & 4.67 & 6.62 & 2.57 & 3.72 & 39.18 & 6.26 & 3.64 & 1.60 & 3.23 & 3.03 & 4.34 \\
\hline Austria & 8.14 & 2.57 & 9.80 & 0.37 & 4.03 & 7.78 & 3.75 & 2.78 & 5.74 & 45.14 & 2.77 & 1.18 & 4.43 & 1.52 & 3.92 \\
\hline Portugal & 4.65 & 1.68 & 5.95 & 1.36 & 4.20 & 5.02 & 4.01 & 0.92 & 5.62 & 3.88 & 59.19 & 0.58 & 1.31 & 1.63 & 2.91 \\
\hline Finland & 4.58 & 1.02 & 7.46 & 0.34 & 3.45 & 5.62 & 1.80 & 1.86 & 2.31 & 2.35 & 0.81 & 63.59 & 2.93 & 1.91 & 2.60 \\
\hline Sweden & 6.72 & 2.53 & 5.89 & 1.28 & 4.61 & 9.01 & 4.76 & 3.05 & 5.12 & 5.68 & 1.59 & 2.99 & 44.09 & 2.69 & 3.99 \\
\hline UK & 4.54 & 1.84 & 3.78 & 0.62 & 5.26 & 5.04 & 3.35 & 1.42 & 3.88 & 2.71 & 3.18 & 1.01 & 1.57 & 61.80 & 2.73 \\
\hline TO & 6.17 & 1.69 & 6.06 & 0.75 & 4.32 & 5.63 & 3.37 & 2.08 & 4.43 & 4.03 & 2.40 & 1.52 & 2.52 & 2.16 & 47.14 \\
\hline
\end{tabular}

All values are percentages.

We next move to the frequency domain examination of the sentiment spillovers between the EU countries based on the BK approach, reported in Table 3. Apart from the difference in the time vs frequency approach, the BK method allows for the determination of spillover changes over time. We selected three bands that correspond to short (4-8 months), medium (8-16 months) and long (above 16 months) term spillovers and are approximately close to the typically used 6-months, 12-months and above 12-months examination of economic analysis. 


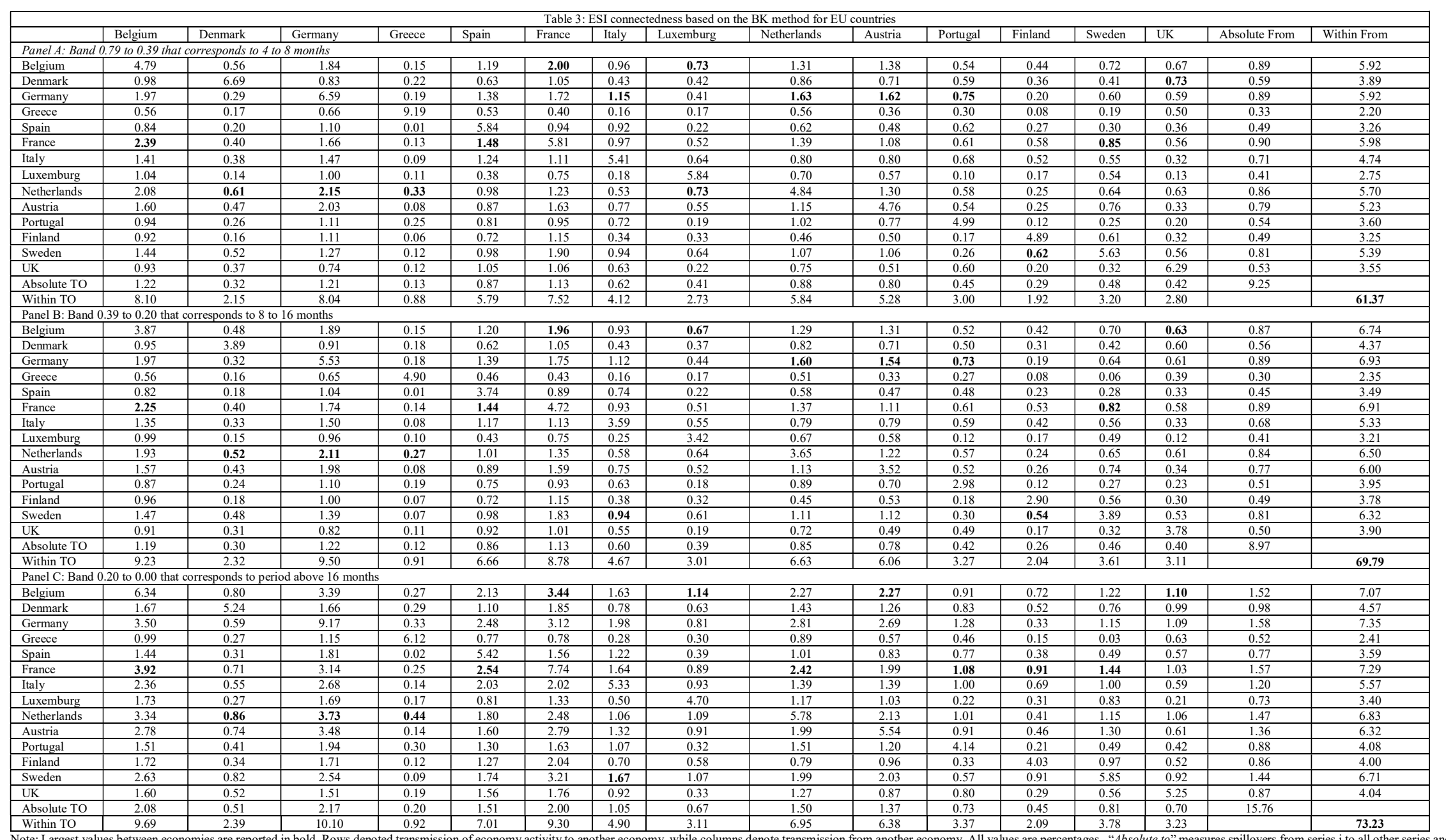

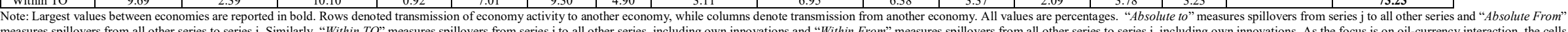

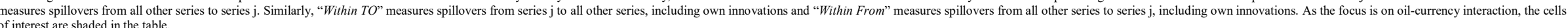


The reported overall connectedness is $61.37 \%, 69.79 \%$ and $73.43 \%$ respectively for the three horizons, suggesting a significant connection between the EU economies that increases as the time horizon extends. In other words, the largest spillovers in economy activity are observed in longer horizons, with a similar pattern observed for the subsectors as reported in Tables A6 to A10 in the Appendix of the paper. When it comes to country level in an across-frequency level, the respective values are significantly lower than the ones reported by the DY method, due to the decomposition technique, leading once again to similar results with the DY method. The economies in the European center are closely linked, while the European south and north hold their unilateral ties. France, Germany and Belgium exhibit the highest transmission percentage (FROM) and acceptance (TO) from the other economies, implying their leading role in the EU economy.

In Figure 1 we depict the evolution of the DY and the BK overall decomposition spillover indices as they evolve through time, based on a rolling window of 60 observations. As we observe the long-term BK decomposition band follows the DY method during the 2008 global financial crisis, suggesting that most of the spillover effect between EU economies can be attributed to the insecurity about the economic future over that period. In contrast, the overall frequency decomposition provides no information over the sovereign crisis in 2010 in the Eurozone, the default of the European south economies and the economic turbulence in the Eurozone. 


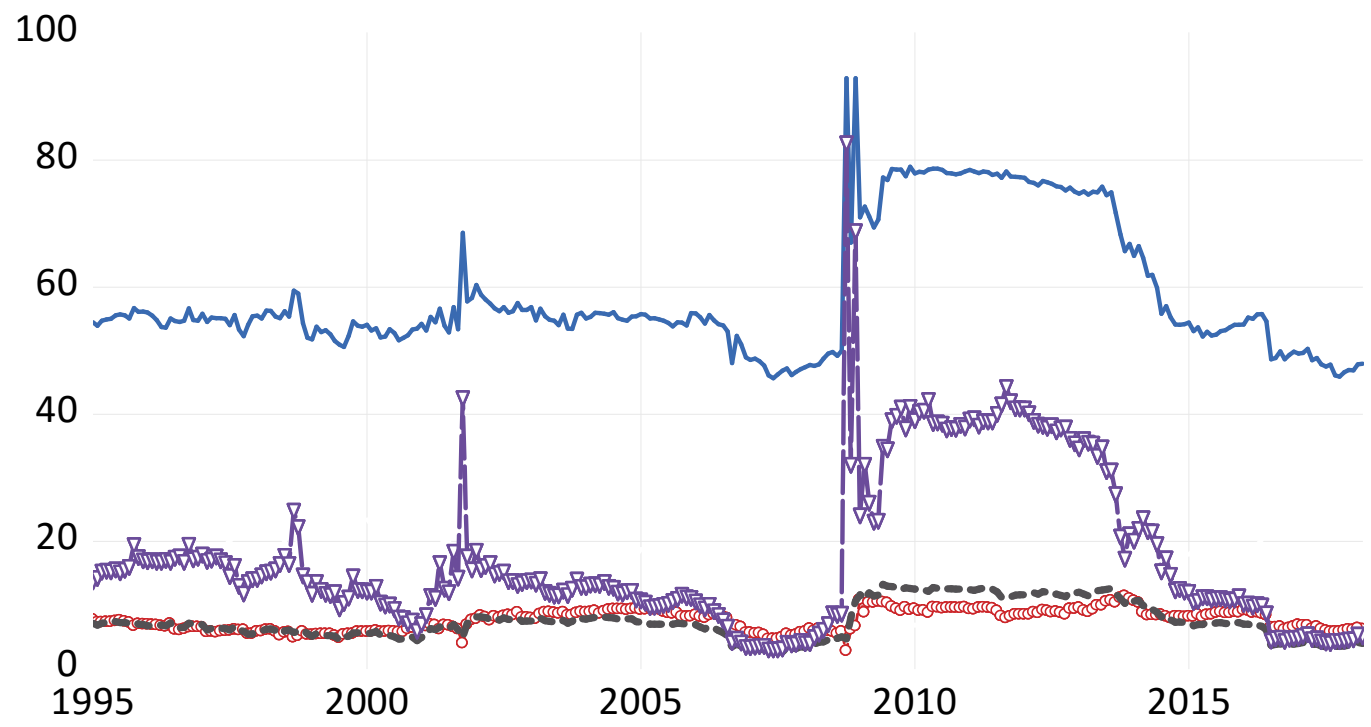

Figure 1: Time evolution of the DY and the BK spillover indices, based on a rolling window estimation. The continuous line represents the DY decomposition index, the dotted line the 4 to 8 months BK decomposition band, the line with the circled marks the 8 to 16 months BK band and the line with the triangular mark the above 16 months band.

To access the net transmitter and receivers of economic sentiment in the EU, we construct the net directional connectedness, reported in Table 4.

\begin{tabular}{|c|c|c|c|c|c|c|c|c|c|c|c|c|c|c|}
\hline \multicolumn{15}{|c|}{ Table 4: ESI net directional connectedness for EU countries } \\
\hline & Belgium & Denmark & Germany & Greece & Spain & France & Italy & Luxemburg & Netherlands & Austria & Portugal & Finland & Sweden & UK \\
\hline \multicolumn{15}{|c|}{ Panel A: Diebold and Yilmaz (2012) method } \\
\hline & 1.67 & -1.20 & 1.77 & -0.93 & 1.43 & 1.26 & -0.31 & -0.26 & 0.09 & 0.11 & -0.52 & -1.08 & -1.48 & -0.56 \\
\hline \multicolumn{15}{|c|}{ Panel B: Barunik and Krehlik (2018) method } \\
\hline 8 to 16 months & 0.32 & -0.26 & 0.33 & -0.19 & 0.41 & 0.24 & -0.08 & -0.03 & 0.02 & 0.01 & -0.09 & -0.22 & -0.35 & -0.10 \\
\hline above 16 months & 0.56 & -0.47 & 0.59 & -0.32 & 0.74 & 0.43 & -0.14 & -0.06 & 0.03 & 0.01 & -0.15 & -0.41 & -0.63 & -0.17 \\
\hline
\end{tabular}

As we observe from the DY method (Panel A of Table 4), Germany (1.77\%), Belgium $(1.67 \%)$, Spain $(1.43 \%)$ and France $(1.26 \%)$ are the main determinants of economic sentiment activity in the EU, while Sweden (-1.48\%), Finland (-1.08\%) and Denmark $(-1.20 \%)$ are the largest followers of economic sentiment-related events. Netherlands $(0.09 \%)$ and Austria $(0.11 \%)$ appear the lowest exposure to the variation of the other economies, which is strange due to the magnitude of these economies and their importance to the EU economy. The results of the BK analysis communicate a similar story, with the effect of the synchronization in economic sentiments being strengthened as we move forward in longer horizons. We elaborate on the paradox of Table 4 regarding the Netherlands and Austria, by examining the rolling window results of the DY decomposition over time for each economy (Figure 2). 


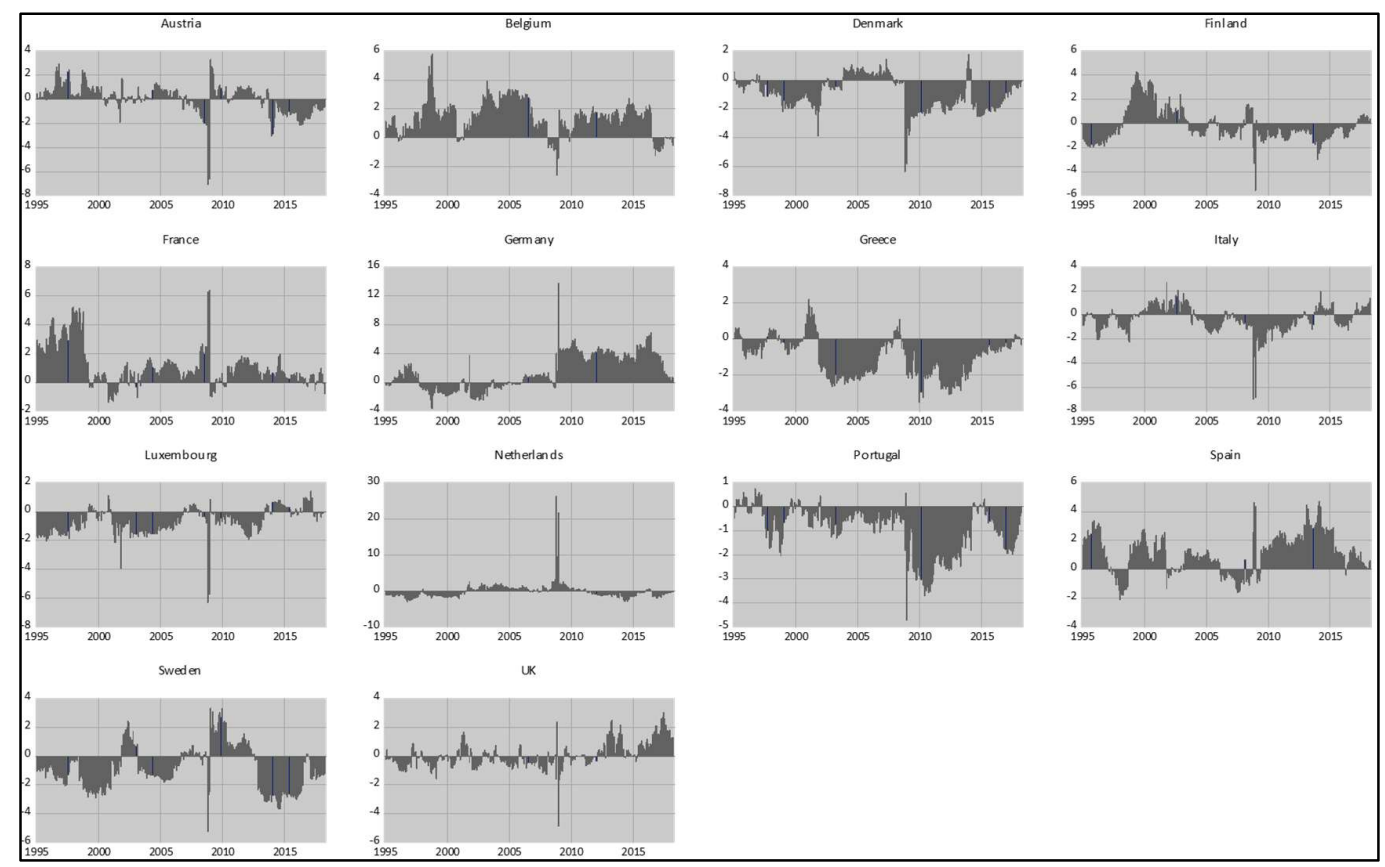

Figure 2: Net directional DY decomposition over time for each country.

As we observe from Figure 2, France has a significant positive net position before 2000 and around the 2008 crisis, while Belgium has a positive net position throughout the examined period. Germany, on the other hand seems to affect the "pace" of the European economic activity only after the 2008 crisis and taking a leading role within the EU. Netherlands exhibits a large peak around 2008 and has more salient parts in the rest of the examined period. Thus, the significance of the economy of Netherlands for the EU economies of the central region discovered in Table 2 is more of a statistical artifact, given that is based entirely on a single period.

The case of Austria is even more interesting, given that it exhibits often transitions between positive and negative net positions and thus we cannot say that the Austrian economy is isolated, but in contrast it is integrated with the rest of the EU economies. One more interesting point is the relevant small fluctuations of the U.K. economy around zero. The fact that the British economy is less impacted by the rest of the European economies (as it is reflected by the business and consumer surveys that are used to construct the indices in our study) suggest that the recent decision of the UK to leave that EU will have a very small imprint on the EU economy (see among others 
Plakandaras et al., 2017; Antonakakis et al., 2018). In contrast, the reverse impact could be distinguished with a similar examination of the British economy and its main trading partners, but we leave this strand for future research.

\section{Concluding Remarks}

In this paper, we study the dynamic relationship between the EU economies as reflected in business and consumer sentiments survey data. In doing so, we use the Diebold and Yilmaz (2012) and the Baruník and Křehlík (2018) decomposition methodologies to observe linkages both in time and frequency domains. Our empirical results confirm the existence of two distinctive regions in terms of business and economic activity synchronization; core EU economies and the economies of the European south. Moreover, Sweden and Finland are less open to fluctuation of the EU region, something also evident for the U.K. In contrast Germany appears to have a dominant role in affecting the economic "pace" within the EU. Overall, our analysis combines two distinctive techniques in a novel way and examines the issue of integration of the EU economies from the perspective of sentiments.

Though there is some degree of segmentation between core and southern European economies, from the perspective of a policymaker negative sentiments originating from Germany are likely to spillover to the rest of the EU, and lead to economic slowdown. In this regard, appropriate expansionary monetary policy and or fiscal policy needs to be implemented. Spillovers of negative sentiments within connected groups would in turn require region-specific policies, possibly other than monetary policy as common interest rate policies for the countries in the Eurozone is set by the European Central Bank. In this regard, policies directed towards the dominant sectors in these economies need to be pursued to revive confidence of agents to prevent the countries from getting into recessionary episodes. 


\section{References}

Antonakakis N., Tondl, G., 2014. Does integration and economic policy coordination promote business cycle synchronization in the EU? Empirica, 41 (3), 541-575.

Antonakakis, N., Gabauer D., Gupta R. and Plakandaras V., 2018. Dynamic connectedness of uncertainty across developed economies: A time-varying approach. Economics Letters, 166, 63-75.

Artis, M., Chouliarakis, G., Harischandra, P. K. G., 2011. Business Cycle Synchronization Since 1880. Manchester School 79 (2), 173-207.

Balcilar, Gupta, R., Kyei, C., 2018. Predicting Stock Returns and Volatility with Investor Sentiment Indices: A Reconsideration Using a Nonparametric CausalityIn-Quantiles Test. Bulletin of Economic Research, 70(1), 74-87.

Baruník, J., Křehlík, T., 2018. Measuring the frequency dynamics of financial connectedness and systemic risk. Journal of Financial Econometrics, 16(2), 271296.

Baruník, J., Křehlík, T., 2018. Measuring the frequency dynamics of financial connectedness and systemic risk. Journal of Financial Econometrics, 16, 271-296.

Bathia D, Bredin D., 2013. An examination of investor sentiment effect on G7 stock market returns. European Journal of Finance, 19, 909-937.

Bathia, D., Bredin, D., and Nitzsche, D., 2016. International sentiment spillovers in equity returns. International Journal of Finance and Economics, 21, 332-359.

Benhabib, J., Liu. X., and Wang, P., 2016. Sentiments, financial markets, and macroeconomic fluctuations. Journal of Financial Economics, 120(2), 420-443.

Baxter, M., Kouparitsas, M.A., 2005. Determinants of Business Cycle Comovement: A Robust Analysis, Journal of Monetary Economics, 52(1), 113-157.

Dew-Becker, I., Giglio, S., 2016. Asset pricing in the frequency domain: theory and empirics. Review of Financial Studies, 29, 2029-2068.

Diebold, F.X., Yilmaz, K., 2012. Better to give than to receive: Predictive directional measurement of volatility spillovers. International Journal of Forecasting, 28, 5766.

Frankel, J.A. and Rose, A.K. 1997. Is EMU More Justifiable Ex Post than Ex Ante, European Economic Review, 41, 753-760.

Krugman, P., 1993. Lessons of Massachusetts for EMU. In Torres, F. and Giavazzi, F. (eds.), Adjustment and Growth in the European Monetary Union. Cambridge: Cambridge University Press.

Papadimitriou T., Gogas P. and Sarantitis G.A., 2016. Convergence of European Business Cycles: A Complex Networks Approach, Computational Economics, 47 (2), 97-119.

Pesaran, H.M., Shin, Y., 1998. Generalized impulse response analysis in linear multivariate models. Economics Letters, 58, 17-29.

Plakandaras V., Gupta R., Wohar M.E, 2017. The depreciation of the pound postBrexit: Could it have been predicted? Finance Research Letters, 21, 206-213.

Tiwari, A.K., Bathia, D., Bouri, E., Gupta, R., 2018. Investor Sentiment Connectedness: Evidence from Linear and Nonlinear Causality Approaches. University of Pretoria, Department of Economics, Working Paper No. 2018-14.

Verma R, Soydemir G. 2006. The impact of US individual and institutional investor sentiment on foreign stock market. Journal of Behavioural Finance, 7, 128-144. 


\section{Appendix}

\begin{tabular}{|c|c|c|c|c|c|c|c|c|c|c|c|c|c|c|c|c|}
\hline \multicolumn{10}{|c|}{ Table A1: Sentiment connectedness based on the DY method for the industrial sector for EU countries } \\
\hline & Belgium & Denmark & Germany & Greece & Spain & France & Italy & Luxemburg & Netherlands & Austria & Portugal & Finland & Sweden & UK & FROM \\
\hline Belgium & 41.59 & 1.6 & 11.86 & 1.27 & 7.05 & 4.89 & 6.49 & 2.8 & 7.25 & 4.34 & 1.64 & 5.46 & 1.42 & 2.35 & 4.17 \\
\hline Denmark & 3.38 & 61.04 & 8.69 & 0.17 & 3.06 & 5.22 & 3.68 & 1.17 & 4.14 & 3.74 & 2.1 & 2.5 & 0.56 & 0.57 & 2.78 \\
\hline Germany & 7.62 & 1.63 & 34.83 & 0.92 & 6.4 & 8.22 & 11.71 & 2.28 & 8.63 & 5.33 & 4.29 & 4.49 & 2.23 & 1.43 & 4.66 \\
\hline Greece & 3.36 & 0.22 & 5.94 & 69.44 & 4.53 & 2.63 & 2.82 & 0.59 & 2.21 & 1.07 & 3.9 & 1.22 & 0.49 & 1.59 & 2.18 \\
\hline Spain & 6.78 & 0.18 & 8.94 & 3.16 & 52.65 & 4.58 & 5.97 & 2.13 & 3.29 & 4.2 & 1.97 & 2.92 & 1.27 & 1.96 & 3.38 \\
\hline France & 6.47 & 1.08 & 15.26 & 0.43 & 5.31 & 42 & 6.39 & 2.53 & 7.47 & 3.1 & 2.41 & 4.75 & 2.12 & 0.69 & 4.14 \\
\hline Italy & 6.58 & 0.93 & 16.57 & 0.52 & 6.74 & 6.18 & 41.46 & 2.12 & 5.72 & 3.11 & 2.63 & 4.5 & 2.24 & 0.7 & 4.18 \\
\hline Luxemburg & 4.36 & 0.53 & 5.62 & 1.06 & 3.06 & 2.92 & 2.92 & 65 & 2.98 & 3.63 & 0.85 & 3.02 & 3.02 & 1.01 & 2.5 \\
\hline Netherlands & 8.54 & 1.75 & 14.22 & 1.59 & 5.03 & 7.68 & 6.8 & 3.76 & 36.28 & 4.4 & 3.9 & 3.36 & 1.41 & 1.29 & 4.55 \\
\hline Austria & 5.31 & 1.75 & 14.18 & 0.48 & 3.42 & 5.66 & 5.88 & 2.82 & 5.48 & 47.99 & 2.79 & 2.47 & 1.29 & 0.47 & 3.71 \\
\hline Portugal & 3.8 & 0.25 & 7.82 & 1.8 & 3.52 & 3.77 & 4.06 & 1.42 & 8.07 & 2.39 & 58.42 & 2.96 & 1.26 & 0.45 & 2.97 \\
\hline Finland & 5.97 & 0.67 & 8.74 & 0.55 & 4.7 & 4.07 & 2.9 & 2.76 & 3.07 & 1.85 & 0.85 & 59.85 & 2.6 & 1.43 & 2.87 \\
\hline Sweden & 4.57 & 0.54 & 10.2 & 0.4 & 3.43 & 5.72 & 5.5 & 0.84 & 4.56 & 2.56 & 1.06 & 3.09 & 56.85 & 0.67 & 3.08 \\
\hline UK & 3.92 & 1.46 & 6.36 & 1.28 & 3.39 & 2.62 & 3.33 & 3.23 & 2.18 & 1.42 & 1.14 & 2.79 & 0.9 & 66 & 2.43 \\
\hline TO & 5.05 & 0.9 & 9.6 & 0.97 & 4.26 & 4.58 & 4.89 & 2.03 & 4.65 & 2.94 & 2.11 & 3.11 & 1.49 & 1.04 & 47.61 \\
\hline Note: See Notes to Table 2.
\end{tabular}

\begin{tabular}{|c|c|c|c|c|c|c|c|c|c|c|c|c|c|c|}
\hline \multicolumn{10}{|c|}{ Table A2: Sentiment connectedness based on the DY method for the service sector for EU countries } \\
\hline & Belgium & Germany & Greece & Spain & France & Italy & Netherlands & Austria & Portugal & Finland & Sweden & UK & FROM \\
\hline Belgium & 24.25 & 11 & 5.29 & 4.1 & 12.9 & 6.1 & 8.63 & 6.02 & 3.13 & 5.17 & 6.86 & 6.54 & 6.31 \\
\hline Germany & 4.41 & 25.9 & 7.54 & 6.21 & 10.4 & 7.04 & 5.24 & 4.85 & 3.36 & 10.95 & 9.95 & 4.14 & 6.17 \\
\hline Greece & 5.96 & 9.48 & 30.02 & 3.75 & 6.98 & 7.07 & 5.22 & 3.77 & 4.85 & 7.7 & 8.19 & 7 & 5.83 \\
\hline Spain & 6.54 & 11.09 & 9.25 & 29.05 & 5.82 & 4.47 & 4.11 & 7.28 & 5.38 & 4.44 & 6.25 & 6.31 & 5.91 \\
\hline France & 5.04 & 10.9 & 5.72 & 2.5 & 27.36 & 8.84 & 2.61 & 4.17 & 4.34 & 14.17 & 7.52 & 6.82 & 6.05 \\
\hline Italy & 5.25 & 6.41 & 4.39 & 7.55 & 4.57 & 32.84 & 3.38 & 3.75 & 4.12 & 10.02 & 5.09 & 12.62 & 5.6 \\
\hline Netherlands & 5.46 & 12.63 & 6.71 & 4.17 & 6.4 & 5.99 & 27.03 & 3.09 & 7.19 & 7.83 & 7.69 & 5.81 & 6.08 \\
\hline Austria & 6.36 & 8.93 & 4.82 & 4.97 & 7.49 & 13.04 & 5.64 & 25.48 & 5.91 & 9.18 & 3.94 & 4.24 & 6.21 \\
\hline Portugal & 4.91 & 6.42 & 7.38 & 8.2 & 6.8 & 5.6 & 8 & 3.31 & 29.4 & 7.07 & 5.21 & 7.71 & 5.88 \\
\hline Finland & 3.74 & 10.77 & 6.72 & 5.97 & 8.54 & 8.42 & 4.42 & 6.99 & 7.69 & 27.09 & 5.57 & 4.07 & 6.08 \\
\hline Sweden & 5.82 & 9.52 & 6.59 & 6.87 & 6.3 & 9.8 & 3.28 & 2.44 & 5.68 & 10 & 25.19 & 8.51 & 6.23 \\
\hline UK & 7.06 & 6.73 & 4.7 & 5.66 & 7.07 & 9.52 & 5.37 & 4.95 & 4.48 & 8.71 & 8.19 & 27.55 & 6.04 \\
\hline TO & 5.05 & 8.66 & 5.76 & 5 & 6.94 & 7.16 & 4.66 & 4.22 & 4.68 & 7.94 & 6.21 & 6.15 & 72.4 \\
\hline
\end{tabular}

\begin{tabular}{|c|c|c|c|c|c|c|c|c|c|c|c|c|c|c|}
\hline \multicolumn{10}{|c|}{ Table A3: Sentiment connectedness based on the D method for the consumers for EU countries } \\
\hline & Belgium & Germany & Greece & Spain & rance & Italy & Netherlands & Austria & Portugal & Finland & Sweden & UK & FROM \\
\hline Belgium & 64.03 & 2.49 & 2.42 & 1.17 & 4.05 & 5.34 & 1.27 & 6.37 & 2.93 & 1.25 & 4.02 & 2.88 & 1.77 \\
\hline Germany & 2.31 & 73.18 & 0.22 & 1.83 & 2.29 & 3.62 & 1.76 & 2.03 & 0.61 & 1.95 & 1.45 & 2.08 & 6.68 \\
\hline Greece & 3.76 & 0.2 & 66 & 0.4 & 3.58 & 3.16 & 2.29 & 0.9 & 7.42 & 0.98 & 7.03 & 4.04 & 0.24 \\
\hline Spain & 0.77 & 0.62 & 0.03 & 86.77 & 1.76 & 1.64 & 1.41 & 1.41 & 1.27 & 1.86 & 1.32 & 0.43 & 0.71 \\
\hline France & 4.68 & 2.12 & 1.84 & 0.47 & 74.22 & 3.48 & 2.21 & 2.42 & 0.11 & 2.9 & 1.89 & 0.64 & 3.01 \\
\hline Italy & 6.18 & 3.67 & 1.55 & 1.22 & 3.6 & 69.76 & 0.09 & 1.66 & 1.83 & 1.13 & 3.8 & 2.35 & 3.16 \\
\hline Netherlands & 1.34 & 2.13 & 0.84 & 1.31 & 4.28 & 0.02 & 81 & 1.89 & 0.87 & 2.12 & 1.74 & 0.6 & 1.85 \\
\hline Austria & 6.81 & 2.52 & 0.62 & 1.35 & 2.62 & 1.97 & 1.96 & 65.7 & 2.83 & 3.5 & 4.58 & 4.58 & 0.95 \\
\hline Portugal & 3.74 & 1.22 & 6.44 & 1.11 & 3.2 & 4.1 & 0.66 & 4.28 & 57.42 & 2.96 & 7.55 & 6.93 & 0.38 \\
\hline
\end{tabular}




\begin{tabular}{|c|c|c|c|c|c|c|c|c|c|c|c|c|c|}
\hline Finland & 2.04 & 1.69 & 0.82 & 1.03 & 7.08 & 1.75 & 1.34 & 2.74 & 2.68 & 68.14 & 4.35 & 2.3 & 4.04 \\
\hline Sweden & 3.27 & 2.09 & 4.26 & 1.41 & 1.5 & 2.94 & 1.37 & 4.14 & 6.42 & 2.66 & 64.25 & 4.75 & 0.92 \\
\hline UK & 2.48 & 4.48 & 2.79 & 0.76 & 1.45 & 2.77 & 0.72 & 2.74 & 6.18 & 1.39 & 6.12 & 66.37 & 1.75 \\
\hline TO & 2.72 & 6.81 & 0.14 & 0.68 & 4.65 & 3.82 & 2.14 & 1.34 & 0.57 & 3.13 & 0.98 & 1.36 & 71.67 \\
\hline
\end{tabular}

Note: See Notes to Table 2 .

\begin{tabular}{|c|c|c|c|c|c|c|c|c|c|c|c|c|c|c|c|c|}
\hline \multicolumn{10}{|c|}{ Table A4: Sentiment connectedness based on the DY method for the retail sector for EU countries } \\
\hline & Belgium & Germany & Greece & Spain & France & Italy & Netherlands & Austria & Portugal & Finland & Sweden & UK & FROM \\
\hline Belgium & 76.63 & 3.69 & 0.27 & 1.56 & 5.41 & 0.9 & 0.73 & 2.49 & 0.34 & 2.76 & 3.12 & 2.11 & 1.95 \\
\hline Germany & 3.54 & 73.75 & 2.06 & 0.18 & 0.55 & 3.97 & 2.93 & 2.64 & 1.71 & 0.93 & 3.07 & 4.66 & 2.19 \\
\hline Greece & 0.6 & 2.52 & 85.83 & 0.27 & 0.19 & 0.38 & 0.82 & 4.39 & 2.12 & 0.03 & 1.69 & 1.18 & 1.18 \\
\hline Spain & 1.45 & 0.26 & 0.15 & 86.91 & 3.31 & 0.78 & 0.02 & 2.59 & 1.89 & 1.12 & 0.58 & 0.93 & 1.09 \\
\hline France & 5.32 & 6.11 & 0.25 & 1.83 & 79.49 & 0.15 & 1.99 & 1.99 & 0.68 & 0.51 & 1.36 & 0.33 & 1.71 \\
\hline Italy & 0.95 & 3.12 & 0.44 & 0.26 & 0.64 & 90.53 & 0.73 & 0.86 & 0.41 & 0.63 & 0.52 & 0.91 & 0.79 \\
\hline Netherlands & 0.9 & 3.45 & 0.67 & 0.07 & 1.88 & 0.65 & 81.97 & 0.35 & 2.19 & 1.99 & 3.91 & 1.98 & 1.5 \\
\hline Austria & 1.43 & 2.31 & 2.31 & 2.86 & 0.08 & 0.09 & 0.56 & 77.11 & 1.16 & 5.53 & 5.09 & 1.47 & 1.91 \\
\hline Portugal & 1.15 & 1.05 & 0.65 & 1.91 & 1.47 & 0.4 & 1.62 & 1.31 & 85.85 & 0.39 & 2.36 & 1.85 & 1.18 \\
\hline Finland & 2.53 & 0.89 & 0.02 & 0.71 & 0.66 & 0.61 & 1.96 & 6.42 & 0.2 & 78.88 & 5.68 & 1.45 & 1.76 \\
\hline Sweden & 4.15 & 3.48 & 1.49 & 0.12 & 1 & 0.33 & 4.49 & 4.36 & 4.23 & 4.86 & 69.29 & 2.19 & 2.56 \\
\hline UK & 1.71 & 5.72 & 0.75 & 0.38 & 0.1 & 0.4 & 2.58 & 1.83 & 1.74 & 1.46 & 3.31 & 80.01 & 1.67 \\
\hline TO & 1.98 & 2.72 & 0.75 & 0.85 & 1.27 & 0.72 & 1.54 & 2.44 & 1.39 & 1.68 & 2.56 & 1.59 & 19.48 \\
\hline
\end{tabular}

\begin{tabular}{|c|c|c|c|c|c|c|c|c|c|c|c|c|c|c|c|c|c|c|}
\hline \multicolumn{10}{|c|}{ Table A5: Sentiment connectedness based on the DY method for the building sector for EU countries } \\
\hline & Belgium & Denmark & Germany & Greece & Spain & France & Italy & Luxemburg & Netherlands & Austria & Portugal & Finland & Sweden & UK & FROM \\
\hline Belgium & 27.27 & 3.92 & 5.38 & 9.35 & 6.89 & 5.13 & 6.77 & 6.75 & 5.6 & 3.61 & 2.65 & 3.47 & 4.9 & 8.3 & 5.19 \\
\hline Denmark & 4.27 & 31.1 & 6.7 & 6.95 & 5.69 & 7.66 & 4.98 & 4.82 & 4.47 & 4.29 & 2.18 & 4.51 & 5.59 & 6.8 & 4.92 \\
\hline Germany & 4.91 & 4.62 & 36.84 & 8.15 & 4.02 & 3.8 & 7.68 & 5.82 & 5.75 & 2.61 & 4.1 & 3.52 & 4.38 & 3.8 & 4.51 \\
\hline Grece & 6.21 & 4.3 & 5.85 & 29.96 & 5.76 & 5.59 & 4.97 & 9.56 & 4.02 & 4.31 & 4.66 & 3.32 & 5.45 & 6.05 & 5 \\
\hline Spain & 5.86 & 7.35 & 4.99 & 4.17 & 31.04 & 6.42 & 3.17 & 9.31 & 4.92 & 4.74 & 4.12 & 3.95 & 4.54 & 5.43 & 4.93 \\
\hline France & 5.66 & 6.07 & 6.4 & 10.28 & 8.42 & 25.88 & 5.02 & 4.58 & 5.79 & 3.3 & 4.52 & 4.69 & 3.79 & 5.6 & 5.29 \\
\hline Italy & 3.92 & 8.45 & 9.86 & 3.09 & 6.31 & 4.01 & 29.35 & 4.7 & 3.22 & 4.59 & 2.19 & 5.62 & 6.37 & 8.32 & 5.05 \\
\hline Luxemburg & 3.94 & 5.55 & 4.94 & 5.69 & 5.02 & 6.38 & 5.61 & 29.76 & 8.62 & 4.74 & 5.15 & 3.79 & 3.12 & 7.7 & 5.02 \\
\hline Netherlands & 4.72 & 5.98 & 5.73 & 5.9 & 8.49 & 5.04 & 4.24 & 6.92 & 28.16 & 4.56 & 4.5 & 4.1 & 4.01 & 7.65 & 5.13 \\
\hline Austria & 7.36 & 6.74 & 5.71 & 5.74 & 4.52 & 5.36 & 3.86 & 5.84 & 4.98 & 28.94 & 2.98 & 3.46 & 8.38 & 6.14 & 5.08 \\
\hline Portugal & 3.78 & 6.8 & 5.16 & 4.81 & 9.18 & 8.97 & 4.99 & 10.43 & 5.14 & 4.52 & 23.03 & 5.89 & 3.41 & 3.91 & 5.5 \\
\hline Finland & 2.77 & 5.87 & 5.23 & 4.9 & 6.31 & 7.83 & 3.23 & 7.73 & 5.08 & 6.5 & 4.09 & 31.8 & 4.84 & 3.81 & 4.87 \\
\hline Sweden & 5.79 & 4.02 & 6.61 & 5.57 & 5.48 & 6.95 & 5.68 & 3.8 & 8.68 & 2.42 & 4.27 & 4.55 & 28.86 & 7.33 & 5.08 \\
\hline UK & 7.12 & 5.41 & 6.21 & 8.28 & 3.5 & 4.88 & 5.25 & 6.37 & 6.52 & 5.99 & 2.26 & 5.68 & 4.26 & 28.26 & 5.12 \\
\hline TO & 4.74 & 5.36 & 5.63 & 5.92 & 5.69 & 5.57 & 4.68 & 6.19 & 5.2 & 4.01 & 3.4 & 4.04 & 4.5 & 5.77 & 70.7 \\
\hline
\end{tabular}




\begin{tabular}{|c|c|c|c|c|c|c|c|c|c|c|c|c|c|c|c|c|}
\hline \multicolumn{17}{|c|}{$\begin{array}{l}\text { Table A6: Sentiment connected } \\
\text { Panel A: The spillover table for band: } 3.14 \text { to } 1.57 \text { that roughly corresponds to } 1 \text { days to } 2 \text { month }\end{array}$} \\
\hline & Belgium & Denmark & Germany & Greece & Spain & France & Italy & Luxembourg & Netherlands & Austria & Portugal & Finland & Sweden & UK & FROM_ABS & FROM_WTH \\
\hline Belgium & 19.60 & 0.30 & 1.18 & 0.46 & 1.51 & 0.63 & 0.87 & 0.37 & 1.80 & 0.72 & 0.30 & 0.95 & 0.86 & 0.51 & 0.75 & 2.02 \\
\hline Denmark & 0.21 & 35.63 & 0.51 & 0.02 & 0.64 & 0.98 & 0.17 & 0.09 & 0.42 & 0.48 & 0.74 & 0.14 & 0.09 & 0.06 & 0.33 & 0.88 \\
\hline Germany & 0.73 & 0.45 & 8.95 & 0.13 & 0.80 & 0.96 & 1.77 & 0.19 & 0.83 & 0.70 & 0.52 & 0.32 & 0.33 & 0.21 & 0.57 & 1.54 \\
\hline Greece & 0.46 & 0.03 & 0.47 & 33.73 & 0.75 & 0.27 & 0.18 & 0.01 & 0.22 & 0.30 & 0.51 & 0.05 & 0.21 & 0.46 & 0.28 & 0.76 \\
\hline Spain & 3.16 & 0.04 & 1.88 & 2.72 & 33.68 & 1.26 & 2.28 & 0.53 & 0.61 & 1.36 & 0.53 & 0.58 & 0.61 & 1.02 & 1.19 & 3.21 \\
\hline France & 0.64 & 0.15 & 1.58 & 0.10 & 0.69 & 19.80 & 0.55 & 0.37 & 1.17 & 0.24 & 0.19 & 0.54 & 0.63 & 0.07 & 0.49 & 1.34 \\
\hline Italy & 0.84 & 0.18 & 2.71 & 0.26 & 1.01 & 0.84 & 19.11 & 0.18 & 0.48 & 0.34 & 0.35 & 0.93 & 0.37 & 0.22 & 0.62 & 1.68 \\
\hline Luxembourg & 0.45 & 0.07 & 0.36 & 0.33 & 0.79 & 0.18 & 0.65 & 39.79 & 0.42 & 1.03 & 0.03 & 1.20 & 2.03 & 0.39 & 0.57 & 1.53 \\
\hline Netherlands & 1.06 & 0.31 & 0.97 & 0.23 & 0.45 & 0.84 & 0.55 & 0.59 & 15.66 & 0.48 & 1.18 & 0.17 & 0.58 & 0.13 & 0.54 & 1.46 \\
\hline Austria & 1.12 & 0.56 & 1.82 & 0.22 & 0.55 & 0.95 & 0.53 & 0.68 & 0.84 & 30.67 & 0.30 & 0.12 & 0.19 & 0.05 & 0.57 & 1.53 \\
\hline Portugal & 0.47 & 0.07 & 0.99 & 1.33 & 0.66 & 0.48 & 0.43 & 0.17 & 1.48 & 0.24 & 34.96 & 0.97 & 0.44 & 0.19 & 0.57 & 1.53 \\
\hline Finland & 2.12 & 0.18 & 0.95 & 0.11 & 1.21 & 1.34 & 0.21 & 0.76 & 0.29 & 0.15 & 0.08 & 36.07 & 0.56 & 0.33 & 0.59 & 1.61 \\
\hline Sweden & 0.51 & 0.03 & 0.68 & 0.23 & 0.38 & 0.66 & 0.42 & 0.10 & 0.39 & 0.47 & 0.05 & 0.29 & 33.91 & 0.27 & 0.32 & 0.87 \\
\hline UK & 0.55 & 0.64 & 0.75 & 0.57 & 0.98 & 0.23 & 0.45 & 1.16 & 0.26 & 0.15 & 0.07 & 0.40 & 0.39 & 45.14 & 0.47 & 1.28 \\
\hline TO_ABS & 0.88 & 0.21 & 1.06 & 0.48 & 0.74 & 0.69 & 0.65 & 0.37 & 0.66 & 0.47 & 0.35 & 0.47 & 0.52 & 0.28 & 7.84 & \\
\hline TO_WTH & 2.39 & 0.58 & 2.87 & 1.30 & 2.02 & 1.86 & 1.76 & 1.01 & 1.78 & 1.29 & 0.94 & 1.29 & 1.41 & 0.75 & & 21.25 \\
\hline Net & 0.13 & -0.11 & 0.49 & 0.20 & -0.44 & 0.19 & 0.03 & -0.19 & 0.12 & -0.09 & -0.22 & -0.12 & 0.20 & -0.19 & & \\
\hline \multicolumn{17}{|c|}{ Panel B: The spillover table for band: 1.57 to 0.79 that roughly corresponds to 2 days to 4 months } \\
\hline Belgium & 8.02 & 0.38 & 2.21 & 0.23 & 1.40 & 0.83 & 1.20 & 0.60 & 1.14 & 0.85 & 0.19 & 1.11 & 0.05 & 0.56 & 0.77 & 4.28 \\
\hline Denmark & 0.57 & 11.94 & 1.52 & 0.01 & 0.54 & 1.01 & 0.62 & 0.22 & 0.77 & 0.74 & 0.37 & 0.47 & 0.05 & 0.09 & 0.50 & 2.78 \\
\hline Germany & 1.34 & 0.23 & 6.15 & 0.18 & 1.07 & 1.44 & 2.13 & 0.33 & 1.60 & 0.95 & 0.84 & 0.76 & 0.39 & 0.27 & 0.82 & 4.59 \\
\hline Greece & 0.58 & 0.03 & 1.09 & 16.88 & 0.95 & 0.50 & 0.51 & 0.09 & 0.28 & 0.21 & 1.01 & 0.22 & 0.18 & 0.34 & 0.43 & 2.38 \\
\hline Spain & 0.94 & 0.01 & 1.66 & 0.21 & 8.22 & 0.83 & 0.87 & 0.44 & 0.56 & 0.88 & 0.41 & 0.63 & 0.13 & 0.31 & 0.56 & 3.14 \\
\hline France & 1.24 & 0.21 & 2.87 & 0.04 & 0.93 & 7.68 & 1.17 & 0.48 & 1.25 & 0.57 & 0.44 & 0.93 & 0.29 & 0.10 & 0.75 & 4.19 \\
\hline
\end{tabular}




\begin{tabular}{|c|c|c|c|c|c|c|c|c|c|c|c|c|c|c|c|c|}
\hline Italy & 1.29 & 0.15 & 3.01 & 0.05 & 1.42 & 1.22 & 7.71 & 0.39 & 1.10 & 0.53 & 0.51 & 0.90 & 0.46 & 0.06 & 0.79 & 4.41 \\
\hline Luxembourg & 0.92 & 0.11 & 0.85 & 0.25 & 0.39 & 0.55 & 0.29 & 11.54 & 0.42 & 0.60 & 0.13 & 0.29 & 0.34 & 0.12 & 0.38 & 2.10 \\
\hline Netherlands & 1.58 & 0.39 & 2.50 & 0.40 & 0.90 & 1.38 & 1.19 & 0.77 & 6.52 & 0.77 & 0.44 & 0.55 & 0.08 & 0.26 & 0.80 & 4.46 \\
\hline Austria & 0.68 & 0.31 & 2.69 & 0.08 & 0.43 & 1.06 & 1.10 & 0.42 & 0.80 & 6.65 & 0.57 & 0.42 & 0.26 & 0.06 & 0.63 & 3.53 \\
\hline Portugal & 0.75 & 0.05 & 1.23 & 0.16 & 0.72 & 0.73 & 0.77 & 0.30 & 1.86 & 0.46 & 10.60 & 0.54 & 0.22 & 0.02 & 0.56 & 3.11 \\
\hline Finland & 0.84 & 0.11 & 1.63 & 0.12 & 0.91 & 0.44 & 0.48 & 0.52 & 0.49 & 0.34 & 0.15 & 10.22 & 0.63 & 0.32 & 0.50 & 2.78 \\
\hline Sweden & 0.84 & 0.09 & 1.91 & 0.07 & 0.62 & 1.14 & 1.03 & 0.15 & 0.80 & 0.46 & 0.18 & 0.51 & 10.47 & 0.13 & 0.57 & 3.16 \\
\hline UK & 0.67 & 0.26 & 1.11 & 0.21 & 0.42 & 0.48 & 0.58 & 0.59 & 0.26 & 0.25 & 0.21 & 0.53 & 0.18 & 10.15 & 0.41 & 2.29 \\
\hline TO_ABS & 0.88 & 0.17 & 1.73 & 0.14 & 0.76 & 0.83 & 0.85 & 0.38 & 0.81 & 0.54 & 0.39 & 0.56 & 0.23 & 0.19 & 8.47 & \\
\hline TO_WTH & 4.88 & 0.93 & 9.66 & 0.80 & 4.26 & 4.62 & 4.76 & 2.11 & 4.51 & 3.03 & 2.16 & 3.12 & 1.29 & 1.05 & & 47.19 \\
\hline Net & 0.11 & -0.33 & 0.91 & -0.28 & 0.20 & 0.08 & 0.06 & 0.00 & 0.01 & -0.09 & -0.17 & 0.06 & -0.33 & -0.22 & & \\
\hline \multicolumn{17}{|c|}{ Panel C: The spillover table for band: 0.79 to 0.39 that roughly corresponds to 4 days to 8 months } \\
\hline Belgium & 5.30 & 0.33 & 2.69 & 0.20 & 1.38 & 1.07 & 1.41 & 0.61 & 1.36 & 0.91 & 0.34 & 1.13 & 0.14 & 0.46 & 0.86 & 5.52 \\
\hline Denmark & 0.80 & 5.98 & 2.07 & 0.03 & 0.60 & 1.06 & 0.89 & 0.28 & 0.94 & 0.82 & 0.33 & 0.60 & 0.12 & 0.13 & 0.62 & 3.99 \\
\hline Germany & 1.74 & 0.29 & 6.46 & 0.20 & 1.41 & 1.83 & 2.50 & 0.53 & 1.97 & 1.16 & 0.95 & 1.06 & 0.48 & 0.31 & 1.03 & 6.64 \\
\hline Greece & 0.73 & 0.05 & 1.38 & 8.67 & 0.96 & 0.59 & 0.67 & 0.15 & 0.50 & 0.19 & 0.87 & 0.30 & 0.07 & 0.28 & 0.48 & 3.09 \\
\hline Spain & 0.88 & 0.03 & 1.77 & 0.07 & 4.40 & 0.82 & 0.91 & 0.40 & 0.68 & 0.70 & 0.35 & 0.58 & 0.18 & 0.22 & 0.54 & 3.49 \\
\hline France & 1.47 & 0.23 & 3.44 & 0.08 & 1.16 & 5.36 & 1.47 & 0.54 & 1.59 & 0.72 & 0.56 & 1.06 & 0.38 & 0.16 & 0.92 & 5.92 \\
\hline Italy & 1.44 & 0.19 & 3.48 & 0.06 & 1.44 & 1.34 & 5.41 & 0.49 & 1.33 & 0.70 & 0.57 & 0.89 & 0.47 & 0.12 & 0.89 & 5.76 \\
\hline Luxembourg & 0.99 & 0.12 & 1.34 & 0.18 & 0.57 & 0.69 & 0.57 & 5.84 & 0.64 & 0.65 & 0.21 & 0.45 & 0.23 & 0.16 & 0.49 & 3.13 \\
\hline Netherlands & 1.89 & 0.36 & 3.35 & 0.35 & 1.15 & 1.73 & 1.57 & 0.79 & 4.99 & 0.99 & 0.69 & 0.81 & 0.20 & 0.29 & 1.01 & 6.51 \\
\hline Austria & 1.06 & 0.29 & 3.11 & 0.06 & 0.73 & 1.18 & 1.35 & 0.53 & 1.18 & 4.07 & 0.63 & 0.60 & 0.27 & 0.11 & 0.79 & 5.11 \\
\hline Portugal & 0.84 & 0.04 & 1.73 & 0.10 & 0.71 & 0.82 & 0.91 & 0.31 & 1.64 & 0.54 & 5.43 & 0.49 & 0.20 & 0.06 & 0.60 & 3.87 \\
\hline Finland & 0.94 & 0.12 & 1.96 & 0.11 & 0.86 & 0.69 & 0.68 & 0.48 & 0.70 & 0.43 & 0.19 & 5.54 & 0.51 & 0.27 & 0.57 & 3.65 \\
\hline Sweden & 1.02 & 0.13 & 2.41 & 0.04 & 0.77 & 1.27 & 1.29 & 0.19 & 1.05 & 0.52 & 0.26 & 0.71 & 5.34 & 0.10 & 0.70 & 4.49 \\
\hline UK & 0.85 & 0.20 & 1.41 & 0.17 & 0.61 & 0.60 & 0.72 & 0.51 & 0.49 & 0.32 & 0.27 & 0.60 & 0.12 & 4.76 & 0.49 & 3.17 \\
\hline
\end{tabular}




\begin{tabular}{|c|c|c|c|c|c|c|c|c|c|c|c|c|c|c|c|c|}
\hline TO_ABS & 1.05 & 0.17 & 2.15 & 0.12 & 0.88 & 0.98 & 1.07 & 0.42 & 1.00 & 0.62 & 0.44 & 0.66 & 0.24 & 0.19 & 9.99 & \\
\hline TO_WTH & 6.73 & 1.09 & 13.86 & 0.76 & 5.68 & 6.30 & 6.88 & 2.67 & 6.47 & 3.98 & 2.86 & 4.26 & 1.55 & 1.23 & & 64.33 \\
\hline Net & & 0.19 & -0.45 & 1.12 & -0.36 & 0.34 & 0.06 & 0.17 & -0.07 & -0.01 & -0.17 & -0.16 & 0.09 & -0.46 & -0.30 & \\
\hline \multicolumn{17}{|c|}{ Panel D: The spillover table for band: 0.39 to 0.20 that roughly corresponds to 8 days to 16 months } \\
\hline Belgium & 3.59 & 0.24 & 2.27 & 0.15 & 1.10 & 0.93 & 1.19 & 0.49 & 1.16 & 0.74 & 0.31 & 0.90 & 0.14 & 0.34 & 0.71 & 5.97 \\
\hline Denmark & 0.70 & 3.31 & 1.80 & 0.04 & 0.50 & 0.86 & 0.78 & 0.23 & 0.79 & 0.67 & 0.26 & 0.51 & 0.11 & 0.11 & 0.53 & 4.42 \\
\hline Germany & 1.50 & 0.25 & 5.27 & 0.16 & 1.22 & 1.57 & 2.09 & 0.48 & 1.67 & 0.99 & 0.79 & 0.92 & 0.40 & 0.25 & 0.88 & 7.37 \\
\hline Greece & 0.62 & 0.05 & 1.18 & 4.58 & 0.75 & 0.50 & 0.57 & 0.13 & 0.46 & 0.15 & 0.62 & 0.26 & 0.02 & 0.21 & 0.39 & 3.31 \\
\hline Spain & 0.71 & 0.04 & 1.44 & 0.06 & 2.70 & 0.66 & 0.75 & 0.31 & 0.57 & 0.51 & 0.27 & 0.45 & 0.14 & 0.17 & 0.43 & 3.65 \\
\hline France & 1.23 & 0.19 & 2.90 & 0.08 & 0.99 & 3.76 & 1.26 & 0.45 & 1.36 & 0.62 & 0.48 & 0.88 & 0.33 & 0.14 & 0.78 & 6.54 \\
\hline Italy & 1.19 & 0.16 & 2.91 & 0.06 & 1.15 & 1.10 & 3.79 & 0.42 & 1.11 & 0.60 & 0.48 & 0.71 & 0.37 & 0.12 & 0.74 & 6.22 \\
\hline Luxembourg & 0.80 & 0.09 & 1.20 & 0.12 & 0.51 & 0.59 & 0.54 & 3.39 & 0.58 & 0.54 & 0.19 & 0.42 & 0.17 & 0.13 & 0.42 & 3.53 \\
\hline Netherlands & 1.58 & 0.28 & 2.90 & 0.25 & 0.99 & 1.47 & 1.36 & 0.64 & 3.69 & 0.85 & 0.62 & 0.71 & 0.21 & 0.24 & 0.86 & 7.26 \\
\hline Austria & 0.95 & 0.23 & 2.60 & 0.05 & 0.66 & 0.98 & 1.14 & 0.47 & 1.04 & 2.74 & 0.51 & 0.52 & 0.22 & 0.10 & 0.68 & 5.68 \\
\hline Portugal & 0.69 & 0.03 & 1.52 & 0.08 & 0.57 & 0.68 & 0.77 & 0.25 & 1.25 & 0.45 & 3.20 & 0.39 & 0.16 & 0.07 & 0.49 & 4.14 \\
\hline Finland & 0.81 & 0.10 & 1.65 & 0.08 & 0.68 & 0.62 & 0.60 & 0.39 & 0.62 & 0.36 & 0.17 & 3.41 & 0.37 & 0.21 & 0.48 & 4.00 \\
\hline Sweden & 0.86 & 0.11 & 2.05 & 0.03 & 0.66 & 1.05 & 1.09 & 0.16 & 0.91 & 0.44 & 0.23 & 0.62 & 3.09 & 0.07 & 0.59 & 4.95 \\
\hline UK & 0.72 & 0.15 & 1.21 & 0.13 & 0.54 & 0.51 & 0.62 & 0.39 & 0.45 & 0.28 & 0.23 & 0.50 & 0.09 & 2.62 & 0.42 & 3.49 \\
\hline TO ABS & 0.88 & 0.14 & 1.83 & 0.09 & 0.74 & 0.82 & 0.91 & 0.34 & 0.86 & 0.51 & 0.37 & 0.56 & 0.20 & 0.15 & 8.40 & \\
\hline TO_WTH & 7.42 & 1.16 & 15.36 & 0.78 & 6.19 & 6.91 & 7.65 & 2.88 & 7.18 & 4.32 & 3.09 & 4.67 & 1.64 & 1.29 & & 70.54 \\
\hline Net & 0.17 & -0.39 & 0.95 & -0.30 & 0.30 & 0.04 & 0.17 & -0.08 & -0.01 & -0.16 & -0.13 & 0.08 & -0.39 & -0.26 & & \\
\hline \multicolumn{17}{|c|}{ Panel E: The spillover table for band: 0.20 to 0.00 that roughly corresponds to more than 16 months } \\
\hline Belgium & 5.08 & 0.35 & 3.50 & 0.23 & 1.66 & 1.44 & 1.82 & 0.73 & 1.80 & 1.12 & 0.49 & 1.37 & 0.24 & 0.49 & 1.09 & 6.14 \\
\hline Denmark & 1.10 & 4.19 & 2.79 & 0.06 & 0.77 & 1.31 & 1.22 & 0.36 & 1.22 & 1.02 & 0.39 & 0.78 & 0.18 & 0.18 & 0.81 & 4.58 \\
\hline Germany & 2.31 & 0.39 & 8.01 & 0.25 & 1.89 & 2.42 & 3.21 & 0.75 & 2.57 & 1.52 & 1.20 & 1.43 & 0.62 & 0.39 & 1.36 & 7.65 \\
\hline Greece & 0.96 & 0.07 & 1.82 & 5.58 & 1.12 & 0.77 & 0.89 & 0.21 & 0.73 & 0.23 & 0.89 & 0.40 & 0.01 & 0.31 & 0.60 & 3.39 \\
\hline
\end{tabular}




\begin{tabular}{|c|c|c|c|c|c|c|c|c|c|c|c|c|c|c|c|c|}
\hline Spain & 1.08 & 0.06 & 2.19 & 0.09 & 3.64 & 1.01 & 1.15 & 0.46 & 0.87 & 0.75 & 0.40 & 0.67 & 0.22 & 0.25 & 0.66 & 3.71 \\
\hline France & 1.89 & 0.29 & 4.46 & 0.12 & 1.53 & 5.40 & 1.94 & 0.69 & 2.10 & 0.95 & 0.74 & 1.35 & 0.50 & 0.22 & 1.20 & 6.77 \\
\hline Italy & 1.82 & 0.25 & 4.46 & 0.10 & 1.72 & 1.68 & 5.44 & 0.64 & 1.70 & 0.93 & 0.73 & 1.07 & 0.56 & 0.19 & 1.13 & 6.40 \\
\hline Luxembourg & 1.21 & 0.14 & 1.88 & 0.17 & 0.80 & 0.91 & 0.87 & 4.43 & 0.92 & 0.82 & 0.30 & 0.67 & 0.25 & 0.21 & 0.65 & 3.68 \\
\hline Netherlands & 2.43 & 0.41 & 4.51 & 0.36 & 1.53 & 2.26 & 2.12 & 0.97 & 5.41 & 1.31 & 0.97 & 1.12 & 0.34 & 0.37 & 1.34 & 7.54 \\
\hline Austria & 1.50 & 0.36 & 3.98 & 0.07 & 1.05 & 1.49 & 1.76 & 0.73 & 1.62 & 3.86 & 0.78 & 0.82 & 0.34 & 0.16 & 1.05 & 5.90 \\
\hline Portugal & 1.05 & 0.05 & 2.36 & 0.13 & 0.86 & 1.05 & 1.18 & 0.38 & 1.85 & 0.69 & 4.23 & 0.58 & 0.24 & 0.11 & 0.75 & 4.25 \\
\hline Finland & 1.26 & 0.16 & 2.54 & 0.12 & 1.03 & 0.99 & 0.93 & 0.59 & 0.97 & 0.56 & 0.25 & 4.61 & 0.53 & 0.31 & 0.73 & 4.13 \\
\hline Sweden & 1.33 & 0.17 & 3.15 & 0.03 & 1.01 & 1.61 & 1.68 & 0.24 & 1.41 & 0.67 & 0.35 & 0.96 & 4.04 & 0.11 & 0.91 & 5.13 \\
\hline UK & 1.12 & 0.22 & 1.87 & 0.19 & 0.84 & 0.79 & 0.96 & 0.58 & 0.72 & 0.43 & 0.36 & 0.76 & 0.12 & 3.33 & 0.64 & 3.61 \\
\hline TO_ABS & 1.36 & 0.21 & 2.82 & 0.14 & 1.13 & 1.26 & 1.41 & 0.52 & 1.32 & 0.79 & 0.56 & 0.86 & 0.30 & 0.23 & 12.91 & \\
\hline TO_WTH & 7.68 & 1.18 & 15.93 & 0.78 & 6.37 & 7.14 & 7.95 & 2.95 & 7.44 & 4.44 & 3.17 & 4.83 & 1.68 & 1.32 & & 72.88 \\
\hline Net & 0.27 & -0.60 & 1.47 & -0.46 & 0.47 & 0.07 & 0.27 & -0.13 & -0.02 & -0.26 & -0.19 & 0.12 & -0.61 & -0.41 & & \\
\hline
\end{tabular}

\begin{tabular}{|c|c|c|c|c|c|c|c|c|c|c|c|c|c|c|}
\hline \multicolumn{15}{|c|}{ Table A7: Sentiment connectedness based on the BK method for the service sector for EU countries } \\
\hline Panel A: The & illover table & for band: 3.14 & 1.57 that rou & hly corre. & onds to 1 & ys to $2 \mathrm{~m}$ & & & & & & & & \\
\hline & Belgium & Germany & Greece & Spain & France & Italy & Netherlands & Austria & Portugal & Finland & Sweden & UK & FROM_ABS & FROM_WTH \\
\hline Belgium & 20.40 & 10.21 & 4.19 & 3.79 & 12.20 & 5.64 & 7.81 & 5.38 & 2.66 & 4.41 & 5.79 & 5.22 & 5.61 & 6.35 \\
\hline Germany & 3.19 & 22.91 & 6.96 & 5.80 & 9.94 & 6.26 & 4.02 & 4.26 & 2.53 & 9.09 & 9.29 & 3.00 & 5.36 & 6.07 \\
\hline Greece & 3.90 & 6.82 & 24.83 & 3.22 & 5.90 & 6.20 & 4.28 & 3.03 & 3.74 & 5.66 & 7.22 & 6.01 & 4.67 & 5.29 \\
\hline Spain & 6.31 & 10.76 & 8.74 & 27.50 & 5.57 & 4.29 & 3.95 & 6.95 & 4.88 & 4.13 & 5.97 & 5.96 & 5.63 & 6.37 \\
\hline France & 4.41 & 9.17 & 5.12 & 1.84 & 22.78 & 7.89 & 1.69 & 3.79 & 3.57 & 12.19 & 6.03 & 5.38 & 5.09 & 5.77 \\
\hline Italy & 4.28 & 5.60 & 4.11 & 7.11 & 4.16 & 30.04 & 2.79 & 3.31 & 3.44 & 8.72 & 3.73 & 11.00 & 4.86 & 5.50 \\
\hline Netherlands & 4.56 & 11.45 & 5.77 & 3.65 & 5.22 & 5.06 & 22.88 & 2.48 & 5.77 & 6.31 & 6.00 & 4.56 & 5.07 & 5.74 \\
\hline Austria & 4.70 & 8.61 & 4.23 & 4.70 & 6.99 & 12.66 & 5.05 & 22.73 & 5.55 & 8.84 & 3.21 & 3.94 & 5.71 & 6.47 \\
\hline Portugal & 4.28 & 4.95 & 6.63 & 7.86 & 6.01 & 5.25 & 7.38 & 3.18 & 26.44 & 6.32 & 4.77 & 6.98 & 5.30 & 6.01 \\
\hline
\end{tabular}




\begin{tabular}{|c|c|c|c|c|c|c|c|c|c|c|c|c|c|c|}
\hline Finland & 3.56 & 10.22 & 6.16 & 5.84 & 8.03 & 8.10 & 4.02 & 6.76 & 7.41 & 25.22 & 5.12 & 3.58 & 5.73 & 6.50 \\
\hline Sweden & 5.59 & 7.11 & 5.28 & 5.89 & 5.24 & 9.44 & 2.33 & 2.09 & 4.92 & 8.41 & 20.83 & 7.48 & 5.31 & 6.02 \\
\hline UK & 6.79 & 5.97 & 4.41 & 5.17 & 6.58 & 8.80 & 4.84 & 4.66 & 3.69 & 8.27 & 7.66 & 25.75 & 5.57 & 6.31 \\
\hline TO_ABS & 4.30 & 7.57 & 5.13 & 4.57 & 6.32 & 6.63 & 4.01 & 3.82 & 4.01 & 6.86 & 5.40 & 5.26 & 63.90 & \\
\hline TO_WTH & 4.87 & 8.58 & 5.82 & 5.18 & 7.16 & 7.51 & 4.55 & 4.33 & 4.55 & 7.78 & 6.12 & 5.96 & & 72.40 \\
\hline Net & -1.31 & 2.21 & 0.47 & -1.05 & 1.23 & 1.78 & -1.06 & -1.88 & -1.29 & 1.13 & 0.08 & -0.31 & & \\
\hline \multicolumn{15}{|c|}{ Panel B: The spillover table for band: 1.57 to 0.79 that roughly corresponds to 2 days to 4 months } \\
\hline Belgium & 3.42 & 0.60 & 0.95 & 0.20 & 0.39 & 0.39 & 0.63 & 0.51 & 0.43 & 0.70 & 0.83 & 1.21 & 0.57 & 5.88 \\
\hline Germany & 0.97 & 2.43 & 0.46 & 0.20 & 0.37 & 0.72 & 0.50 & 0.37 & 0.72 & 1.43 & 0.32 & 0.95 & 0.59 & 6.03 \\
\hline Greece & 1.90 & 2.49 & 4.16 & 0.24 & 0.88 & 0.73 & 0.58 & 0.68 & 1.06 & 1.78 & 0.79 & 0.94 & 1.01 & 10.38 \\
\hline Spain & 0.21 & 0.31 & 0.47 & 1.33 & 0.21 & 0.17 & 0.14 & 0.32 & 0.49 & 0.29 & 0.27 & 0.28 & 0.26 & 2.72 \\
\hline France & 0.28 & 1.28 & 0.39 & 0.33 & 3.28 & 0.64 & 0.35 & 0.16 & 0.63 & 1.73 & 1.14 & 1.17 & 0.67 & 6.96 \\
\hline Italy & 0.84 & 0.68 & 0.13 & 0.37 & 0.34 & 2.43 & 0.43 & 0.36 & 0.59 & 1.25 & 1.15 & 1.51 & 0.64 & 6.57 \\
\hline Netherlands & 0.37 & 0.90 & 0.70 & 0.32 & 0.84 & 0.87 & 3.16 & 0.47 & 1.11 & 1.30 & 1.16 & 0.96 & 0.75 & 7.72 \\
\hline Austria & 1.56 & 0.21 & 0.55 & 0.14 & 0.28 & 0.33 & 0.45 & 2.56 & 0.32 & 0.29 & 0.58 & 0.24 & 0.41 & 4.26 \\
\hline Portugal & 0.56 & 1.44 & 0.70 & 0.33 & 0.68 & 0.33 & 0.57 & 0.11 & 2.81 & 0.73 & 0.35 & 0.68 & 0.54 & 5.57 \\
\hline Finland & 0.17 & 0.49 & 0.47 & 0.09 & 0.45 & 0.32 & 0.34 & 0.18 & 0.27 & 1.78 & 0.42 & 0.47 & 0.31 & 3.15 \\
\hline Sweden & 0.14 & 2.06 & 1.14 & 0.94 & 0.80 & 0.25 & 0.73 & 0.26 & 0.70 & 1.54 & 3.81 & 0.95 & 0.79 & 8.16 \\
\hline UK & 0.23 & 0.73 & 0.26 & 0.43 & 0.45 & 0.67 & 0.48 & 0.27 & 0.78 & 0.42 & 0.48 & 1.58 & 0.43 & 4.48 \\
\hline TO_ABS & 0.60 & 0.93 & 0.52 & 0.30 & 0.48 & 0.45 & 0.43 & 0.31 & 0.59 & 0.95 & 0.62 & 0.78 & 6.97 & \\
\hline TO_WTH & 6.21 & 9.62 & 5.35 & 3.09 & 4.90 & 4.65 & 4.47 & 3.19 & 6.08 & 9.84 & 6.43 & 8.02 & & 71.87 \\
\hline Net & 0.03 & 0.35 & -0.49 & 0.04 & -0.20 & -0.19 & -0.31 & -0.10 & 0.05 & 0.65 & -0.17 & 0.34 & & \\
\hline \multicolumn{15}{|c|}{ Panel C: The spillover table for band: 0.79 to 0.39 that roughly corresponds to 4 days to 8 months } \\
\hline Belgium & 0.31 & 0.09 & 0.12 & 0.08 & 0.20 & 0.06 & 0.10 & 0.10 & 0.04 & 0.04 & 0.11 & 0.08 & 0.09 & 5.44 \\
\hline Germany & 0.23 & 0.39 & 0.11 & 0.17 & 0.07 & 0.05 & 0.66 & 0.17 & 0.11 & 0.42 & 0.23 & 0.17 & 0.20 & 12.67 \\
\hline Greece & 0.12 & 0.12 & 0.93 & 0.28 & 0.18 & 0.14 & 0.35 & 0.04 & 0.05 & 0.25 & 0.16 & 0.05 & 0.15 & 9.20 \\
\hline
\end{tabular}




\begin{tabular}{|c|c|c|c|c|c|c|c|c|c|c|c|c|c|c|}
\hline Spain & 0.02 & 0.01 & 0.03 & 0.19 & 0.04 & 0.01 & 0.02 & 0.01 & 0.01 & 0.01 & 0.01 & 0.05 & 0.02 & 1.14 \\
\hline France & 0.25 & 0.25 & 0.14 & 0.29 & 0.99 & 0.30 & 0.44 & 0.17 & 0.13 & 0.23 & 0.14 & 0.25 & 0.21 & 13.59 \\
\hline Italy & 0.12 & 0.12 & 0.14 & 0.05 & 0.06 & 0.33 & 0.14 & 0.08 & 0.09 & 0.05 & 0.19 & 0.09 & 0.09 & 5.99 \\
\hline Netherlands & 0.49 & 0.15 & 0.18 & 0.16 & 0.14 & 0.06 & 0.69 & 0.13 & 0.27 & 0.15 & 0.29 & 0.16 & 0.18 & 11.52 \\
\hline Austria & 0.09 & 0.06 & 0.02 & 0.11 & 0.18 & 0.05 & 0.10 & 0.14 & 0.04 & 0.04 & 0.06 & 0.04 & 0.07 & 4.18 \\
\hline Portugal & 0.04 & 0.02 & 0.05 & 0.01 & 0.07 & 0.01 & 0.03 & 0.01 & 0.13 & 0.01 & 0.06 & 0.04 & 0.03 & 1.92 \\
\hline Finland & 0.02 & 0.05 & 0.08 & 0.04 & 0.05 & 0.01 & 0.05 & 0.05 & 0.01 & 0.08 & 0.02 & 0.02 & 0.03 & 2.12 \\
\hline Sweden & 0.07 & 0.22 & 0.13 & 0.03 & 0.18 & 0.10 & 0.16 & 0.07 & 0.06 & 0.04 & 0.33 & 0.06 & 0.09 & 5.89 \\
\hline UK & 0.04 & 0.02 & 0.03 & 0.05 & 0.02 & 0.04 & 0.03 & 0.01 & 0.01 & 0.01 & 0.03 & 0.19 & 0.02 & 1.50 \\
\hline TO_ABS & 0.12 & 0.09 & 0.09 & 0.11 & 0.10 & 0.07 & 0.17 & 0.07 & 0.07 & 0.10 & 0.11 & 0.08 & 1.19 & \\
\hline TO_WTH & 7.87 & 5.85 & 5.41 & 6.72 & 6.29 & 4.39 & 11.00 & 4.50 & 4.27 & 6.61 & 6.87 & 5.38 & & 75.14 \\
\hline Net & 0.04 & -0.11 & -0.06 & 0.09 & -0.12 & -0.03 & -0.01 & 0.01 & 0.04 & 0.07 & 0.02 & 0.06 & & \\
\hline \multicolumn{15}{|c|}{ Panel D: The spillover table for band: 0.39 to 0.20 that roughly corresponds to 8 days to 16 months } \\
\hline Belgium & 0.10 & 0.07 & 0.02 & 0.02 & 0.09 & 0.01 & 0.07 & 0.02 & 0.00 & 0.01 & 0.11 & 0.02 & 0.04 & 10.63 \\
\hline Germany & 0.03 & 0.14 & 0.00 & 0.02 & 0.01 & 0.00 & 0.05 & 0.04 & 0.01 & 0.01 & 0.10 & 0.01 & 0.02 & 6.85 \\
\hline Greece & 0.03 & 0.04 & 0.07 & 0.00 & 0.02 & 0.00 & 0.00 & 0.01 & 0.00 & 0.01 & 0.01 & 0.00 & 0.01 & 2.97 \\
\hline Spain & 0.00 & 0.01 & 0.01 & 0.02 & 0.01 & 0.00 & 0.00 & 0.00 & 0.00 & 0.00 & 0.00 & 0.01 & 0.00 & 1.10 \\
\hline France & 0.09 & 0.16 & 0.05 & 0.04 & 0.24 & 0.02 & 0.10 & 0.05 & 0.00 & 0.02 & 0.16 & 0.01 & 0.06 & 16.62 \\
\hline Italy & 0.00 & 0.01 & 0.01 & 0.00 & 0.01 & 0.03 & 0.02 & 0.00 & 0.01 & 0.00 & 0.02 & 0.01 & 0.01 & 1.88 \\
\hline Netherlands & 0.03 & 0.09 & 0.04 & 0.01 & 0.18 & 0.00 & 0.17 & 0.01 & 0.04 & 0.06 & 0.20 & 0.09 & 0.06 & 18.02 \\
\hline Austria & 0.01 & 0.04 & 0.01 & 0.01 & 0.03 & 0.00 & 0.03 & 0.04 & 0.00 & 0.01 & 0.07 & 0.01 & 0.02 & 5.07 \\
\hline Portugal & 0.01 & 0.02 & 0.01 & 0.00 & 0.03 & 0.00 & 0.02 & 0.01 & 0.01 & 0.00 & 0.02 & 0.00 & 0.01 & 2.93 \\
\hline Finland & 0.00 & 0.00 & 0.00 & 0.00 & 0.01 & 0.00 & 0.00 & 0.00 & 0.00 & 0.01 & 0.01 & 0.00 & 0.00 & 0.59 \\
\hline Sweden & 0.02 & 0.09 & 0.03 & 0.00 & 0.06 & 0.00 & 0.05 & 0.03 & 0.00 & 0.01 & 0.17 & 0.02 & 0.03 & 7.51 \\
\hline UK & 0.01 & 0.01 & 0.00 & 0.01 & 0.01 & 0.00 & 0.01 & 0.01 & 0.00 & 0.00 & 0.02 & 0.01 & 0.01 & 2.17 \\
\hline TO_ABS & 0.02 & 0.05 & 0.02 & 0.01 & 0.04 & 0.00 & 0.03 & 0.01 & 0.01 & 0.01 & 0.06 & 0.01 & 0.27 & \\
\hline
\end{tabular}




\begin{tabular}{|c|c|c|c|c|c|c|c|c|c|c|c|c|c|c|}
\hline TO_WTH & 5.67 & 12.88 & 4.32 & 2.92 & 10.85 & 0.97 & 8.29 & 4.02 & 1.66 & 3.14 & 17.47 & 4.12 & & 76.32 \\
\hline Net & -0.02 & 0.02 & 0.00 & 0.01 & -0.02 & 0.00 & -0.03 & 0.00 & 0.00 & 0.01 & 0.03 & 0.01 & & \\
\hline \multicolumn{15}{|c|}{ Panel E: The spillover table for band: 0.20 to 0.00 that roughly corresponds to more than 16 months } \\
\hline Belgium & 0.03 & 0.03 & 0.01 & 0.01 & 0.02 & 0.00 & 0.02 & 0.01 & 0.00 & 0.00 & 0.03 & 0.01 & 0.01 & 10.70 \\
\hline Germany & 0.00 & 0.04 & 0.00 & 0.01 & 0.00 & 0.00 & 0.01 & 0.00 & 0.00 & 0.00 & 0.01 & 0.00 & 0.00 & 4.23 \\
\hline Greece & 0.01 & 0.01 & 0.03 & 0.00 & 0.00 & 0.00 & 0.00 & 0.00 & 0.00 & 0.00 & 0.00 & 0.00 & 0.00 & 2.46 \\
\hline Spain & 0.00 & 0.00 & 0.00 & 0.02 & 0.00 & 0.00 & 0.00 & 0.00 & 0.00 & 0.00 & 0.00 & 0.01 & 0.00 & 0.99 \\
\hline France & 0.01 & 0.05 & 0.02 & 0.01 & 0.07 & 0.00 & 0.03 & 0.01 & 0.00 & 0.00 & 0.05 & 0.01 & 0.02 & 14.16 \\
\hline Italy & 0.00 & 0.00 & 0.00 & 0.00 & 0.00 & 0.01 & 0.00 & 0.00 & 0.00 & 0.00 & 0.00 & 0.01 & 0.00 & 2.34 \\
\hline Netherlands & 0.00 & 0.03 & 0.02 & 0.02 & 0.02 & 0.00 & 0.12 & 0.00 & 0.01 & 0.01 & 0.04 & 0.04 & 0.02 & 15.37 \\
\hline Austria & 0.00 & 0.02 & 0.00 & 0.01 & 0.01 & 0.00 & 0.01 & 0.02 & 0.00 & 0.00 & 0.02 & 0.01 & 0.01 & 5.79 \\
\hline Portugal & 0.00 & 0.00 & 0.00 & 0.00 & 0.01 & 0.00 & 0.00 & 0.00 & 0.01 & 0.00 & 0.00 & 0.01 & 0.00 & 2.19 \\
\hline Finland & 0.00 & 0.00 & 0.00 & 0.00 & 0.00 & 0.00 & 0.00 & 0.00 & 0.00 & 0.00 & 0.00 & 0.00 & 0.00 & 0.82 \\
\hline Sweden & 0.00 & 0.03 & 0.01 & 0.01 & 0.01 & 0.00 & 0.02 & 0.00 & 0.00 & 0.01 & 0.06 & 0.01 & 0.01 & 7.46 \\
\hline UK & 0.00 & 0.00 & 0.00 & 0.00 & 0.00 & 0.00 & 0.00 & 0.00 & 0.00 & 0.00 & 0.00 & 0.02 & 0.00 & 1.95 \\
\hline TO_ABS & 0.00 & 0.02 & 0.01 & 0.01 & 0.01 & 0.00 & 0.01 & 0.00 & 0.00 & 0.00 & 0.01 & 0.01 & 0.08 & \\
\hline TO_WTH & 2.47 & 13.95 & 4.96 & 5.44 & 5.47 & 1.16 & 7.72 & 1.82 & 1.22 & 3.26 & 12.38 & 8.60 & & 68.46 \\
\hline Net & -0.01 & 0.01 & 0.00 & 0.01 & -0.01 & 0.00 & -0.01 & 0.00 & 0.00 & 0.00 & 0.01 & 0.01 & & \\
\hline
\end{tabular}

\begin{tabular}{|c|c|c|c|c|c|c|c|c|c|c|c|c|c|c|c|}
\hline \multicolumn{16}{|c|}{ Panel A: The spillover table for band: 3.14 to 1.57 that roughly corresponds to 1 days to 2 months } \\
\hline & Belgium & Denmark & Germany & Greece & Spain & France & Italy & Netherlands & Austria & Portugal & Finland & Sweden & UK & FROM_ABS & FROM WTH \\
\hline Belgium & 36.72 & 0.58 & 1.16 & 0.16 & 1.80 & 2.84 & 0.32 & 1.93 & 0.82 & 0.59 & 0.82 & 0.60 & 0.63 & 0.94 & 2.06 \\
\hline Denmark & 0.89 & 45.50 & 0.14 & 0.68 & 0.90 & 1.62 & 0.63 & 1.10 & 0.14 & 0.42 & 0.25 & 0.67 & 3.46 & 0.84 & 1.83 \\
\hline Germany & 0.63 & 0.05 & 27.88 & 0.10 & 0.34 & 0.44 & 0.47 & 0.05 & 1.85 & 0.09 & 1.01 & 0.71 & 0.10 & 0.45 & 0.98 \\
\hline Greece & 0.22 & 0.56 & 0.00 & 45.37 & 0.43 & 0.39 & 0.80 & 0.31 & 0.52 & 0.29 & 0.24 & 0.38 & 0.24 & 0.34 & 0.74 \\
\hline
\end{tabular}




\begin{tabular}{|c|c|c|c|c|c|c|c|c|c|c|c|c|c|c|c|}
\hline Spain & 2.14 & 1.19 & 0.80 & 0.11 & 38.20 & 0.86 & 0.76 & 1.17 & 0.06 & 1.63 & 0.49 & 0.52 & 1.13 & 0.83 & 1.82 \\
\hline France & 1.99 & 1.33 & 0.27 & 0.37 & 0.72 & 38.82 & 0.03 & 0.21 & 0.27 & 0.20 & 0.58 & 0.40 & 1.11 & 0.57 & 1.26 \\
\hline Italy & 0.58 & 1.59 & 0.47 & 0.59 & 1.04 & 0.01 & 45.03 & 1.05 & 0.73 & 0.63 & 0.65 & 0.46 & 0.97 & 0.68 & 1.48 \\
\hline Netherlands & 1.90 & 0.43 & 0.09 & 0.21 & 1.07 & 0.39 & 0.52 & 37.33 & 0.54 & 0.78 & 0.62 & 1.05 & 0.10 & 0.59 & 1.29 \\
\hline Austria & 0.58 & 0.20 & 1.61 & 0.61 & 1.14 & 0.89 & 0.09 & 0.78 & 31.05 & 0.41 & 1.12 & 1.36 & 0.09 & 0.68 & 1.49 \\
\hline Portugal & 0.24 & 0.52 & 0.09 & 0.19 & 1.07 & 0.18 & 0.55 & 0.36 & 0.40 & 29.44 & 0.53 & 0.29 & 0.75 & 0.40 & 0.87 \\
\hline Finland & 1.02 & 0.34 & 1.87 & 0.20 & 0.63 & 0.49 & 0.82 & 0.75 & 1.56 & 1.16 & 33.46 & 1.03 & 0.21 & 0.78 & 1.70 \\
\hline Sweden & 0.43 & 1.16 & 0.99 & 0.06 & 0.23 & 0.44 & 0.12 & 0.48 & 2.46 & 0.16 & 1.12 & 35.24 & 0.32 & 0.61 & 1.34 \\
\hline UK & 0.62 & 2.80 & 0.09 & 0.14 & 0.92 & 0.95 & 0.57 & 0.25 & 0.24 & 1.10 & 0.10 & 0.39 & 42.07 & 0.63 & 1.37 \\
\hline TO_ABS & 0.86 & 0.83 & 0.58 & 0.26 & 0.79 & 0.73 & 0.44 & 0.65 & 0.74 & 0.57 & 0.58 & 0.61 & 0.70 & 8.34 & \\
\hline TO_WTH & 1.89 & 1.81 & 1.27 & 0.57 & 1.73 & 1.60 & 0.95 & 1.42 & 1.61 & 1.25 & 1.27 & 1.32 & 1.53 & & 18.24 \\
\hline Net & -0.08 & -0.01 & 0.13 & -0.08 & -0.04 & 0.16 & -0.24 & 0.06 & 0.05 & 0.18 & -0.20 & -0.01 & 0.07 & & \\
\hline \multicolumn{16}{|c|}{ Panel B: The spillover table for band: 1.57 to 0.79 that roughly corresponds to 2 days to 4 months } \\
\hline Belgium & 13.07 & 0.72 & 0.52 & 0.35 & 0.87 & 0.93 & 0.38 & 1.74 & 0.79 & 0.18 & 1.14 & 0.86 & 0.42 & 0.68 & 2.99 \\
\hline Denmark & 0.54 & 14.02 & 0.04 & 0.48 & 0.44 & 0.75 & 0.49 & 0.29 & 0.16 & 0.56 & 0.39 & 0.55 & 1.41 & 0.47 & 2.05 \\
\hline Germany & 1.02 & 0.07 & 16.67 & 0.09 & 0.99 & 0.87 & 0.68 & 0.23 & 2.03 & 0.25 & 1.95 & 1.13 & 0.08 & 0.72 & 3.16 \\
\hline Greece & 0.17 & 0.03 & 0.01 & 20.06 & 0.49 & 0.41 & 0.28 & 0.40 & 0.26 & 0.56 & 0.34 & 0.01 & 0.14 & 0.24 & 1.04 \\
\hline Spain & 1.12 & 0.45 & 0.45 & 0.15 & 17.13 & 1.10 & 0.65 & 0.54 & 0.01 & 0.62 & 0.56 & 0.07 & 0.84 & 0.51 & 2.22 \\
\hline France & 1.58 & 0.86 & 0.45 & 0.25 & 1.03 & 14.05 & 0.03 & 0.46 & 0.52 & 0.28 & 1.06 & 0.65 & 0.77 & 0.61 & 2.68 \\
\hline Italy & 0.37 & 0.34 & 0.21 & 0.34 & 1.42 & 0.01 & 18.23 & 0.41 & 0.10 & 0.70 & 0.53 & 0.11 & 0.39 & 0.38 & 1.66 \\
\hline Netherlands & 1.82 & 0.70 & 0.16 & 0.37 & 0.36 & 0.46 & 0.55 & 12.57 & 0.73 & 0.95 & 1.24 & 1.29 & 0.24 & 0.68 & 2.99 \\
\hline Austria & 1.02 & 0.33 & 1.77 & 0.08 & 0.72 & 1.08 & 0.17 & 1.16 & 11.56 & 0.81 & 2.06 & 1.89 & 0.08 & 0.86 & 3.77 \\
\hline Portugal & 0.50 & 0.30 & 0.20 & 0.22 & 2.05 & 0.38 & 0.25 & 0.75 & 0.71 & 16.71 & 1.11 & 0.62 & 1.14 & 0.63 & 2.78 \\
\hline Finland & 0.71 & 0.60 & 0.88 & 0.39 & 0.19 & 0.76 & 0.19 & 1.15 & 1.79 & 0.40 & 13.34 & 1.24 & 0.23 & 0.66 & 2.87 \\
\hline Sweden & 0.68 & 1.31 & 0.66 & 0.22 & 0.36 & 0.76 & 0.21 & 0.75 & 1.34 & 0.35 & 1.73 & 14.19 & 0.50 & 0.68 & 2.99 \\
\hline UK & 0.82 & 1.75 & 0.03 & 0.18 & 1.45 & 1.10 & 0.67 & 0.39 & 0.12 & 0.79 & 0.29 & 0.36 & 14.55 & 0.61 & 2.68 \\
\hline
\end{tabular}




\begin{tabular}{|c|c|c|c|c|c|c|c|c|c|c|c|c|c|c|c|}
\hline TO_ABS & 0.80 & 0.57 & 0.41 & 0.24 & 0.80 & 0.66 & 0.35 & 0.64 & 0.66 & 0.50 & 0.95 & 0.68 & 0.48 & 7.73 & \\
\hline TO_WTH & 3.49 & 2.51 & 1.81 & 1.05 & 3.50 & 2.90 & 1.53 & 2.79 & 2.89 & 2.17 & 4.18 & 2.96 & 2.11 & & 33.88 \\
\hline Net & 0.11 & 0.11 & -0.31 & 0.00 & 0.29 & 0.05 & -0.03 & -0.05 & -0.20 & -0.14 & 0.30 & -0.01 & -0.13 & & \\
\hline \multicolumn{16}{|c|}{ Panel C: The spillover table for band: 0.79 to 0.39 that roughly corresponds to 4 days to 8 months } \\
\hline Belgium & 6.65 & 0.52 & 0.32 & 0.29 & 0.59 & 0.67 & 0.25 & 1.18 & 0.57 & 0.19 & 0.88 & 0.62 & 0.31 & 0.49 & 3.49 \\
\hline Denmark & 0.38 & 6.53 & 0.02 & 0.30 & 0.39 & 0.53 & 0.29 & 0.26 & 0.13 & 0.42 & 0.34 & 0.37 & 0.82 & 0.33 & 2.33 \\
\hline Germany & 0.88 & 0.04 & 9.84 & 0.09 & 0.93 & 0.77 & 0.50 & 0.25 & 1.52 & 0.26 & 1.71 & 0.93 & 0.03 & 0.61 & 4.33 \\
\hline Greece & 0.16 & 0.01 & 0.01 & 10.11 & 0.36 & 0.35 & 0.15 & 0.30 & 0.21 & 0.43 & 0.30 & 0.01 & 0.13 & 0.19 & 1.33 \\
\hline Spain & 0.65 & 0.22 & 0.27 & 0.10 & 8.94 & 0.70 & 0.37 & 0.32 & 0.02 & 0.31 & 0.38 & 0.02 & 0.48 & 0.30 & 2.10 \\
\hline France & 1.13 & 0.64 & 0.36 & 0.24 & 0.79 & 7.73 & 0.02 & 0.41 & 0.44 & 0.26 & 0.91 & 0.54 & 0.55 & 0.48 & 3.44 \\
\hline Italy & 0.19 & 0.11 & 0.08 & 0.18 & 0.85 & 0.00 & 8.61 & 0.21 & 0.02 & 0.38 & 0.27 & 0.02 & 0.23 & 0.20 & 1.39 \\
\hline Netherlands & 1.33 & 0.59 & 0.15 & 0.32 & 0.46 & 0.45 & 0.39 & 7.13 & 0.65 & 0.75 & 1.12 & 0.96 & 0.25 & 0.57 & 4.06 \\
\hline Austria & 0.89 & 0.29 & 1.32 & 0.15 & 0.56 & 0.89 & 0.17 & 0.98 & 6.67 & 0.72 & 1.82 & 1.55 & 0.08 & 0.73 & 5.16 \\
\hline Portugal & 0.52 & 0.34 & 0.21 & 0.24 & 1.68 & 0.47 & 0.22 & 0.67 & 0.64 & 9.97 & 1.10 & 0.57 & 0.92 & 0.59 & 4.16 \\
\hline Finland & 0.64 & 0.49 & 0.64 & 0.34 & 0.25 & 0.70 & 0.15 & 0.94 & 1.32 & 0.43 & 7.82 & 1.04 & 0.20 & 0.55 & 3.91 \\
\hline Sweden & 0.57 & 0.88 & 0.49 & 0.20 & 0.35 & 0.65 & 0.17 & 0.63 & 1.01 & 0.35 & 1.39 & 7.78 & 0.40 & 0.55 & 3.88 \\
\hline UK & 0.56 & 1.03 & 0.01 & 0.15 & 1.01 & 0.77 & 0.41 & 0.30 & 0.09 & 0.54 & 0.25 & 0.26 & 7.14 & 0.41 & 2.95 \\
\hline TO_ABS & 0.61 & 0.40 & 0.30 & 0.20 & 0.63 & 0.54 & 0.24 & 0.50 & 0.51 & 0.39 & 0.80 & 0.53 & 0.34 & 5.98 & \\
\hline TO WTH & 4.32 & 2.82 & 2.13 & 1.43 & 4.51 & 3.81 & 1.68 & 3.54 & 3.62 & 2.76 & 5.73 & 3.78 & 2.41 & & 42.55 \\
\hline Net & 0.12 & 0.07 & -0.31 & 0.01 & 0.34 & 0.05 & 0.04 & -0.07 & -0.22 & -0.20 & 0.26 & -0.01 & -0.08 & & \\
\hline \multicolumn{16}{|c|}{ Panel D: The spillover table for band: 0.39 to 0.20 that roughly corresponds to 8 days to 16 months } \\
\hline Belgium & 3.46 & 0.30 & 0.19 & 0.17 & 0.35 & 0.40 & 0.14 & 0.68 & 0.33 & 0.13 & 0.52 & 0.36 & 0.18 & 0.29 & 3.69 \\
\hline Denmark & 0.22 & 3.28 & 0.01 & 0.17 & 0.24 & 0.32 & 0.16 & 0.17 & 0.08 & 0.25 & 0.21 & 0.22 & 0.45 & 0.19 & 2.44 \\
\hline Germany & 0.54 & 0.02 & 5.28 & 0.05 & 0.58 & 0.48 & 0.29 & 0.17 & 0.90 & 0.17 & 1.05 & 0.56 & 0.01 & 0.37 & 4.73 \\
\hline Greece & 0.10 & 0.01 & 0.01 & 5.15 & 0.21 & 0.22 & 0.08 & 0.18 & 0.13 & 0.25 & 0.19 & 0.01 & 0.08 & 0.11 & 1.45 \\
\hline Spain & 0.35 & 0.12 & 0.15 & 0.05 & 4.57 & 0.38 & 0.20 & 0.18 & 0.01 & 0.16 & 0.21 & 0.01 & 0.26 & 0.16 & 2.02 \\
\hline
\end{tabular}




\begin{tabular}{|c|c|c|c|c|c|c|c|c|c|c|c|c|c|c|c|}
\hline France & 0.66 & 0.38 & 0.21 & 0.16 & 0.47 & 4.15 & 0.01 & 0.26 & 0.27 & 0.17 & 0.56 & 0.33 & 0.32 & 0.29 & 3.72 \\
\hline Italy & 0.09 & 0.05 & 0.04 & 0.09 & 0.44 & 0.00 & 4.23 & 0.10 & 0.01 & 0.19 & 0.14 & 0.00 & 0.12 & 0.10 & 1.25 \\
\hline Netherlands & 0.79 & 0.36 & 0.10 & 0.20 & 0.31 & 0.29 & 0.23 & 3.91 & 0.40 & 0.45 & 0.70 & 0.57 & 0.16 & 0.35 & 4.47 \\
\hline Austria & 0.55 & 0.18 & 0.77 & 0.11 & 0.34 & 0.55 & 0.11 & 0.60 & 3.67 & 0.45 & 1.13 & 0.94 & 0.05 & 0.44 & 5.68 \\
\hline Portugal & 0.34 & 0.23 & 0.14 & 0.16 & 1.01 & 0.31 & 0.14 & 0.42 & 0.41 & 5.44 & 0.71 & 0.36 & 0.55 & 0.37 & 4.69 \\
\hline Finland & 0.40 & 0.29 & 0.39 & 0.21 & 0.18 & 0.44 & 0.09 & 0.57 & 0.78 & 0.29 & 4.34 & 0.64 & 0.13 & 0.34 & 4.33 \\
\hline Sweden & 0.35 & 0.50 & 0.29 & 0.13 & 0.22 & 0.40 & 0.10 & 0.39 & 0.61 & 0.23 & 0.84 & 4.16 & 0.24 & 0.33 & 4.22 \\
\hline UK & 0.32 & 0.56 & 0.00 & 0.09 & 0.57 & 0.44 & 0.22 & 0.18 & 0.05 & 0.31 & 0.15 & 0.16 & 3.63 & 0.24 & 3.01 \\
\hline TO ABS & 0.36 & 0.23 & 0.18 & 0.12 & 0.38 & 0.33 & 0.14 & 0.30 & 0.31 & 0.23 & 0.49 & 0.32 & 0.20 & 3.58 & \\
\hline TO_WTH & 4.63 & 2.93 & 2.24 & 1.57 & 4.86 & 4.16 & 1.73 & 3.82 & 3.90 & 2.99 & 6.29 & 4.08 & 2.51 & & 45.70 \\
\hline Net & 0.07 & 0.04 & -0.19 & 0.01 & 0.22 & 0.03 & 0.04 & -0.05 & -0.14 & -0.13 & 0.15 & -0.01 & -0.04 & & \\
\hline \multicolumn{16}{|c|}{ Panel E: The spillover table for band: 0.20 to 0.00 that roughly corresponds to more than 16 months } \\
\hline Belgium & 4.12 & 0.37 & 0.23 & 0.21 & 0.45 & 0.50 & 0.18 & 0.84 & 0.41 & 0.16 & 0.66 & 0.44 & 0.23 & 0.36 & 3.77 \\
\hline Denmark & 0.28 & 3.86 & 0.01 & 0.20 & 0.31 & 0.40 & 0.19 & 0.21 & 0.10 & 0.31 & 0.26 & 0.27 & 0.54 & 0.24 & 2.48 \\
\hline Germany & 0.68 & 0.02 & 6.34 & 0.07 & 0.73 & 0.60 & 0.35 & 0.21 & 1.12 & 0.22 & 1.32 & 0.71 & 0.01 & 0.47 & 4.87 \\
\hline Greece & 0.13 & 0.01 & 0.01 & 6.07 & 0.26 & 0.28 & 0.10 & 0.22 & 0.16 & 0.32 & 0.24 & 0.02 & 0.11 & 0.14 & 1.49 \\
\hline Spain & 0.42 & 0.14 & 0.18 & 0.07 & 5.38 & 0.45 & 0.23 & 0.21 & 0.01 & 0.19 & 0.25 & 0.01 & 0.30 & 0.19 & 1.99 \\
\hline France & 0.82 & 0.47 & 0.27 & 0.20 & 0.59 & 5.00 & 0.01 & 0.32 & 0.34 & 0.22 & 0.70 & 0.42 & 0.40 & 0.37 & 3.82 \\
\hline Italy & 0.11 & 0.05 & 0.04 & 0.11 & 0.52 & 0.00 & 4.91 & 0.12 & 0.01 & 0.22 & 0.16 & 0.00 & 0.14 & 0.11 & 1.19 \\
\hline Netherlands & 0.98 & 0.45 & 0.12 & 0.25 & 0.41 & 0.37 & 0.28 & 4.76 & 0.51 & 0.56 & 0.90 & 0.71 & 0.21 & 0.44 & 4.63 \\
\hline Austria & 0.70 & 0.23 & 0.96 & 0.15 & 0.43 & 0.69 & 0.13 & 0.76 & 4.47 & 0.57 & 1.43 & 1.18 & 0.07 & 0.56 & 5.87 \\
\hline Portugal & 0.44 & 0.30 & 0.18 & 0.21 & 1.26 & 0.40 & 0.18 & 0.53 & 0.52 & 6.58 & 0.91 & 0.46 & 0.69 & 0.47 & 4.88 \\
\hline Finland & 0.51 & 0.37 & 0.48 & 0.27 & 0.24 & 0.56 & 0.12 & 0.72 & 0.97 & 0.38 & 5.29 & 0.80 & 0.16 & 0.43 & 4.49 \\
\hline Sweden & 0.44 & 0.62 & 0.36 & 0.16 & 0.29 & 0.51 & 0.13 & 0.49 & 0.76 & 0.29 & 1.05 & 5.01 & 0.30 & 0.42 & 4.35 \\
\hline UK & 0.39 & 0.67 & 0.00 & 0.12 & 0.70 & 0.55 & 0.27 & 0.22 & 0.07 & 0.39 & 0.19 & 0.20 & 4.28 & 0.29 & 3.02 \\
\hline TO_ABS & 0.45 & 0.28 & 0.22 & 0.16 & 0.48 & 0.41 & 0.17 & 0.37 & 0.38 & 0.29 & 0.62 & 0.40 & 0.24 & 4.48 & \\
\hline
\end{tabular}




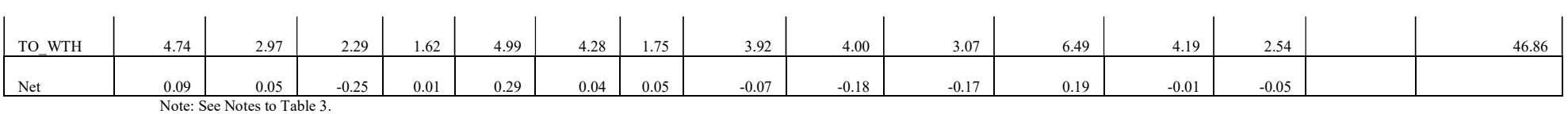

\begin{tabular}{|c|c|c|c|c|c|c|c|c|c|c|c|c|c|c|}
\hline \multicolumn{15}{|c|}{ Table A9: Sentiment connectedness based on the BK method for the retail sector for EU countries } \\
\hline \multicolumn{15}{|c|}{ Panel A: The spillover table for band: 3.14 to 1.57 that roughly corresponds to 1 days to 2 months } \\
\hline & Belgium & Germany & Greece & Spain & France & Italy & Netherlands & Austria & Portugal & Finland & Sweden & UK & FROM_ABS & FROM_WTH \\
\hline Belgium & 49.35 & 2.15 & 0.15 & 1.24 & 3.70 & 0.33 & 0.20 & 2.26 & 0.14 & 2.24 & 1.23 & 0.63 & 1.19 & 1.84 \\
\hline Germany & 2.30 & 50.19 & 1.64 & 0.13 & 0.52 & 3.43 & 2.18 & 1.86 & 1.58 & 0.84 & 2.25 & 2.36 & 1.59 & 2.47 \\
\hline Greece & 0.38 & 0.54 & 36.45 & 0.19 & 0.07 & 0.30 & 0.43 & 1.02 & 0.41 & 0.01 & 0.44 & 0.16 & 0.33 & 0.51 \\
\hline Spain & 1.03 & 0.19 & 0.03 & 58.12 & 3.20 & 0.72 & 0.02 & 1.81 & 1.79 & 0.94 & 0.45 & 0.88 & 0.92 & 1.43 \\
\hline France & 2.37 & 5.00 & 0.15 & 1.72 & 61.53 & 0.11 & 1.07 & 1.81 & 0.31 & 0.37 & 0.93 & 0.24 & 1.17 & 1.82 \\
\hline Italy & 0.52 & 1.98 & 0.40 & 0.12 & 0.63 & 64.32 & 0.28 & 0.71 & 0.15 & 0.54 & 0.22 & 0.46 & 0.50 & 0.78 \\
\hline Netherlands & 0.22 & 2.59 & 0.25 & 0.07 & 0.90 & 0.37 & 56.50 & 0.18 & 0.78 & 1.33 & 2.10 & 1.27 & 0.84 & 1.30 \\
\hline Austria & 0.74 & 1.26 & 1.87 & 2.45 & 0.08 & 0.09 & 0.51 & 58.19 & 0.78 & 3.72 & 4.11 & 0.73 & 1.36 & 2.11 \\
\hline Portugal & 0.70 & 0.39 & 0.33 & 1.79 & 1.24 & 0.15 & 0.56 & 0.67 & 59.63 & 0.36 & 0.85 & 0.63 & 0.64 & 0.99 \\
\hline Finland & 1.98 & 0.59 & 0.01 & 0.47 & 0.63 & 0.53 & 1.12 & 4.66 & 0.14 & 55.79 & 4.49 & 1.19 & 1.32 & 2.05 \\
\hline Sweden & 0.94 & 0.82 & 0.65 & 0.04 & 0.40 & 0.10 & 1.17 & 1.61 & 1.71 & 1.95 & 35.54 & 0.36 & 0.81 & 1.26 \\
\hline UK & 0.52 & 2.37 & 0.70 & 0.17 & 0.07 & 0.18 & 0.81 & 1.20 & 0.73 & 1.12 & 1.03 & 50.41 & 0.74 & 1.15 \\
\hline TO_ABS & 0.97 & 1.49 & 0.51 & 0.70 & 0.95 & 0.53 & 0.70 & 1.48 & 0.71 & 1.12 & 1.51 & 0.74 & 11.41 & \\
\hline TO_WTH & 1.51 & 2.31 & 0.80 & 1.08 & 1.48 & 0.82 & 1.08 & 2.30 & 1.10 & 1.73 & 2.34 & 1.15 & & 17.72 \\
\hline Net & -0.21 & -0.10 & 0.18 & -0.22 & -0.22 & 0.02 & -0.14 & 0.12 & 0.07 & -0.20 & 0.70 & 0.00 & & \\
\hline \multicolumn{15}{|c|}{ Panel B: The spillover table for band: 1.57 to 0.79 that roughly corresponds to 2 days to 4 months } \\
\hline Belgium & 13.89 & 0.69 & 0.08 & 0.19 & 0.84 & 0.26 & 0.20 & 0.11 & 0.08 & 0.27 & 0.72 & 0.64 & 0.34 & 1.91 \\
\hline Germany & 0.68 & 12.84 & 0.30 & 0.03 & 0.02 & 0.33 & 0.43 & 0.46 & 0.11 & 0.07 & 0.46 & 1.23 & 0.34 & 1.93 \\
\hline Greece & 0.16 & 0.69 & 21.94 & 0.04 & 0.04 & 0.06 & 0.10 & 1.36 & 0.61 & 0.01 & 0.47 & 0.35 & 0.32 & 1.82 \\
\hline Spain & 0.21 & 0.05 & 0.05 & 15.44 & 0.08 & 0.05 & 0.00 & 0.35 & 0.04 & 0.08 & 0.07 & 0.03 & 0.08 & 0.48 \\
\hline
\end{tabular}




\begin{tabular}{|c|c|c|c|c|c|c|c|c|c|c|c|c|c|c|}
\hline France & 1.48 & 0.61 & 0.05 & 0.08 & 9.84 & 0.02 & 0.47 & 0.11 & 0.18 & 0.07 & 0.21 & 0.06 & 0.28 & 1.56 \\
\hline Italy & 0.18 & 0.54 & 0.03 & 0.07 & 0.00 & 14.13 & 0.19 & 0.08 & 0.10 & 0.06 & 0.12 & 0.21 & 0.13 & 0.75 \\
\hline Netherlands & 0.28 & 0.38 & 0.16 & 0.00 & 0.48 & 0.12 & 13.31 & 0.06 & 0.62 & 0.34 & 0.74 & 0.29 & 0.29 & 1.63 \\
\hline Austria & 0.38 & 0.57 & 0.32 & 0.23 & 0.00 & 0.00 & 0.03 & 10.70 & 0.24 & 1.02 & 0.60 & 0.40 & 0.32 & 1.78 \\
\hline Portugal & 0.21 & 0.26 & 0.12 & 0.10 & 0.09 & 0.11 & 0.44 & 0.28 & 13.31 & 0.01 & 0.62 & 0.48 & 0.23 & 1.28 \\
\hline Finland & 0.35 & 0.18 & 0.00 & 0.12 & 0.03 & 0.04 & 0.48 & 1.00 & 0.05 & 12.70 & 0.77 & 0.18 & 0.27 & 1.50 \\
\hline Sweden & 1.29 & 1.04 & 0.36 & 0.04 & 0.26 & 0.10 & 1.37 & 1.17 & 1.07 & 1.39 & 15.39 & 0.68 & 0.73 & 4.11 \\
\hline UK & 0.48 & 1.59 & 0.04 & 0.12 & 0.02 & 0.10 & 0.78 & 0.30 & 0.42 & 0.16 & 0.99 & 15.07 & 0.42 & 2.34 \\
\hline TO_ABS & 0.48 & 0.55 & 0.13 & 0.09 & 0.15 & 0.10 & 0.38 & 0.44 & 0.29 & 0.29 & 0.48 & 0.38 & 3.75 & \\
\hline TO_WTH & 2.68 & 3.10 & 0.71 & 0.48 & 0.87 & 0.56 & 2.11 & 2.48 & 1.64 & 1.63 & 2.70 & 2.12 & & 21.08 \\
\hline Net & 0.14 & 0.21 & -0.20 & 0.00 & -0.12 & -0.03 & 0.09 & 0.13 & 0.07 & 0.02 & -0.25 & -0.04 & & \\
\hline & & & roughl. & topon & $24 d a$ & $8 \mathrm{~mol}$ & & & & & & & & \\
\hline Belgium & 6.44 & 0.39 & 0.02 & 0.07 & 0.41 & 0.15 & 0.15 & 0.05 & 0.05 & 0.12 & 0.52 & 0.39 & 0.19 & 2.28 \\
\hline Germany & 0.28 & 5.31 & 0.07 & 0.01 & 0.00 & 0.11 & 0.16 & 0.16 & 0.02 & 0.01 & 0.18 & 0.53 & 0.13 & 1.51 \\
\hline Greece & 0.04 & 0.56 & 12.72 & 0.02 & 0.03 & 0.01 & 0.12 & 0.91 & 0.48 & 0.01 & 0.34 & 0.29 & 0.23 & 2.74 \\
\hline Spain & 0.10 & 0.01 & 0.04 & 6.58 & 0.02 & 0.01 & 0.00 & 0.20 & 0.02 & 0.04 & 0.03 & 0.01 & 0.04 & 0.46 \\
\hline France & 0.71 & 0.25 & 0.02 & 0.02 & 4.01 & 0.01 & 0.22 & 0.04 & 0.09 & 0.03 & 0.10 & 0.02 & 0.12 & 1.47 \\
\hline Italy & 0.11 & 0.28 & 0.01 & 0.03 & 0.00 & 5.94 & 0.12 & 0.04 & 0.07 & 0.02 & 0.08 & 0.11 & 0.07 & 0.85 \\
\hline Netherlands & 0.18 & 0.22 & 0.11 & 0.00 & 0.24 & 0.07 & 5.90 & 0.04 & 0.36 & 0.16 & 0.48 & 0.19 & 0.17 & 2.01 \\
\hline Austria & 0.16 & 0.24 & 0.08 & 0.09 & 0.00 & 0.00 & 0.01 & 4.12 & 0.08 & 0.40 & 0.20 & 0.17 & 0.12 & 1.39 \\
\hline Portugal & 0.11 & 0.18 & 0.09 & 0.01 & 0.06 & 0.07 & 0.28 & 0.16 & 6.19 & 0.01 & 0.40 & 0.33 & 0.14 & 1.68 \\
\hline Finland & 0.10 & 0.06 & 0.00 & 0.06 & 0.00 & 0.02 & 0.18 & 0.38 & 0.01 & 5.15 & 0.23 & 0.05 & 0.09 & 1.07 \\
\hline Sweden & 0.87 & 0.72 & 0.22 & 0.02 & 0.16 & 0.06 & 0.88 & 0.72 & 0.66 & 0.72 & 8.53 & 0.51 & 0.46 & 5.43 \\
\hline UK & 0.32 & 0.83 & 0.00 & 0.05 & 0.01 & 0.06 & 0.46 & 0.16 & 0.27 & 0.09 & 0.59 & 7.00 & 0.24 & 2.78 \\
\hline TO_ABS & 0.25 & 0.31 & 0.05 & 0.03 & 0.08 & 0.05 & 0.21 & 0.24 & 0.18 & 0.13 & 0.26 & 0.22 & 2.01 & \\
\hline TO_WTH & 2.92 & 3.67 & 0.65 & 0.37 & 0.92 & 0.55 & 2.53 & 2.80 & 2.07 & 1.56 & 3.10 & 2.54 & & 23.67 \\
\hline
\end{tabular}




\begin{tabular}{|c|c|c|c|c|c|c|c|c|c|c|c|c|c|c|}
\hline Net & 0.05 & 0.18 & -0.18 & -0.01 & -0.05 & -0.03 & 0.04 & 0.12 & 0.03 & 0.04 & -0.20 & -0.02 & & \\
\hline Belgium & 3.20 & 0.21 & 0.01 & 0.03 & 0.21 & 0.08 & 0.08 & 0.03 & 0.03 & 0.06 & 0.29 & 0.21 & 0.10 & 2.41 \\
\hline Germany & 0.13 & 2.52 & 0.03 & 0.00 & 0.00 & 0.05 & 0.08 & 0.07 & 0.00 & 0.01 & 0.08 & 0.25 & 0.06 & 1.37 \\
\hline Greece & 0.01 & 0.33 & 6.72 & 0.01 & 0.02 & 0.00 & 0.08 & 0.50 & 0.28 & 0.00 & 0.20 & 0.17 & 0.13 & 3.10 \\
\hline Spain & 0.05 & 0.00 & 0.02 & 3.15 & 0.01 & 0.00 & 0.00 & 0.11 & 0.02 & 0.02 & 0.02 & 0.00 & 0.02 & 0.49 \\
\hline France & 0.35 & 0.12 & 0.01 & 0.01 & 1.91 & 0.00 & 0.11 & 0.02 & 0.04 & 0.01 & 0.05 & 0.01 & 0.06 & 1.43 \\
\hline Italy & 0.06 & 0.15 & 0.00 & 0.02 & 0.00 & 2.85 & 0.06 & 0.02 & 0.04 & 0.01 & 0.04 & 0.06 & 0.04 & 0.89 \\
\hline Netherlands & 0.10 & 0.12 & 0.06 & 0.00 & 0.12 & 0.04 & 2.89 & 0.03 & 0.19 & 0.08 & 0.26 & 0.11 & 0.09 & 2.16 \\
\hline Austria & 0.07 & 0.11 & 0.03 & 0.04 & 0.00 & 0.00 & 0.00 & 1.92 & 0.03 & 0.18 & 0.09 & 0.08 & 0.05 & 1.24 \\
\hline Portugal & 0.06 & 0.10 & 0.05 & 0.00 & 0.04 & 0.04 & 0.15 & 0.09 & 3.09 & 0.01 & 0.22 & 0.18 & 0.08 & 1.82 \\
\hline Finland & 0.04 & 0.02 & 0.00 & 0.03 & 0.00 & 0.01 & 0.08 & 0.18 & 0.00 & 2.44 & 0.09 & 0.02 & 0.04 & 0.93 \\
\hline Sweden & 0.48 & 0.40 & 0.12 & 0.01 & 0.09 & 0.03 & 0.48 & 0.39 & 0.36 & 0.37 & 4.49 & 0.29 & 0.25 & 5.88 \\
\hline UK & 0.17 & 0.43 & 0.00 & 0.02 & 0.00 & 0.03 & 0.24 & 0.08 & 0.15 & 0.04 & 0.32 & 3.47 & 0.12 & 2.91 \\
\hline TO_ABS & 0.13 & 0.17 & 0.03 & 0.01 & 0.04 & 0.02 & 0.11 & 0.12 & 0.10 & 0.07 & 0.14 & 0.11 & 1.05 & \\
\hline TO_WTH & 2.98 & 3.88 & 0.63 & 0.33 & 0.95 & 0.55 & 2.67 & 2.92 & 2.24 & 1.55 & 3.24 & 2.68 & & 24.63 \\
\hline Net & 0.02 & 0.11 & -0.11 & -0.01 & -0.02 & -0.01 & 0.02 & 0.07 & 0.02 & 0.03 & -0.11 & -0.01 & & \\
\hline Belgium & 3.74 & 0.25 & 0.01 & 0.03 & 0.25 & 0.09 & 0.10 & 0.03 & 0.04 & 0.07 & 0.35 & 0.25 & 0.12 & 2.45 \\
\hline Germany & 0.15 & 2.89 & 0.03 & 0.00 & 0.00 & 0.05 & 0.09 & 0.08 & 0.00 & 0.01 & 0.09 & 0.29 & 0.07 & 1.32 \\
\hline Greece & 0.01 & 0.40 & 8.00 & 0.01 & 0.03 & 0.00 & 0.10 & 0.60 & 0.34 & 0.01 & 0.24 & 0.21 & 0.16 & 3.22 \\
\hline Spain & 0.06 & 0.00 & 0.02 & 3.62 & 0.01 & 0.00 & 0.00 & 0.13 & 0.02 & 0.03 & 0.02 & 0.01 & 0.03 & 0.50 \\
\hline France & 0.41 & 0.14 & 0.01 & 0.01 & 2.20 & 0.01 & 0.13 & 0.02 & 0.05 & 0.02 & 0.06 & 0.01 & 0.07 & 1.42 \\
\hline Italy & 0.07 & 0.17 & 0.00 & 0.02 & 0.00 & 3.29 & 0.07 & 0.02 & 0.05 & 0.01 & 0.05 & 0.07 & 0.05 & 0.90 \\
\hline Netherlands & 0.12 & 0.14 & 0.08 & 0.00 & 0.14 & 0.05 & 3.36 & 0.03 & 0.23 & 0.09 & 0.32 & 0.13 & 0.11 & 2.21 \\
\hline Austria & 0.08 & 0.13 & 0.03 & 0.05 & 0.00 & 0.00 & 0.00 & 2.18 & 0.04 & 0.21 & 0.10 & 0.09 & 0.06 & 1.19 \\
\hline
\end{tabular}




\begin{tabular}{|c|c|c|c|c|c|c|c|c|c|c|c|c|c|c|}
\hline Portugal & 0.07 & 0.12 & 0.06 & 0.00 & 0.04 & 0.04 & 0.18 & 0.11 & 3.62 & 0.01 & 0.26 & 0.22 & 0.09 & 1.87 \\
\hline Finland & 0.05 & 0.03 & 0.00 & 0.03 & 0.00 & 0.01 & 0.09 & 0.20 & 0.00 & 2.80 & 0.10 & 0.02 & 0.04 & 0.88 \\
\hline Sweden & 0.58 & 0.49 & 0.14 & 0.01 & 0.10 & 0.04 & 0.58 & 0.47 & 0.43 & 0.43 & 5.34 & 0.35 & 0.30 & 6.04 \\
\hline UK & 0.21 & 0.51 & 0.00 & 0.02 & 0.00 & 0.04 & 0.29 & 0.10 & 0.18 & 0.05 & 0.38 & 4.05 & 0.15 & 2.95 \\
\hline TO ABS & 0.15 & 0.20 & 0.03 & 0.02 & 0.05 & 0.03 & 0.14 & 0.15 & 0.11 & 0.08 & 0.16 & 0.14 & 1.25 & \\
\hline TO_WTH & 3.00 & 3.96 & 0.63 & 0.32 & 0.96 & 0.55 & 2.72 & 2.97 & 2.30 & 1.54 & 3.29 & 2.74 & & 24.97 \\
\hline Net & 0.03 & 0.13 & -0.13 & -0.01 & -0.02 & -0.02 & 0.03 & 0.09 & 0.02 & 0.03 & -0.14 & -0.01 & & \\
\hline
\end{tabular}

Table A10: Sentiment connectedness based on the BK method for the building sector for EU countries

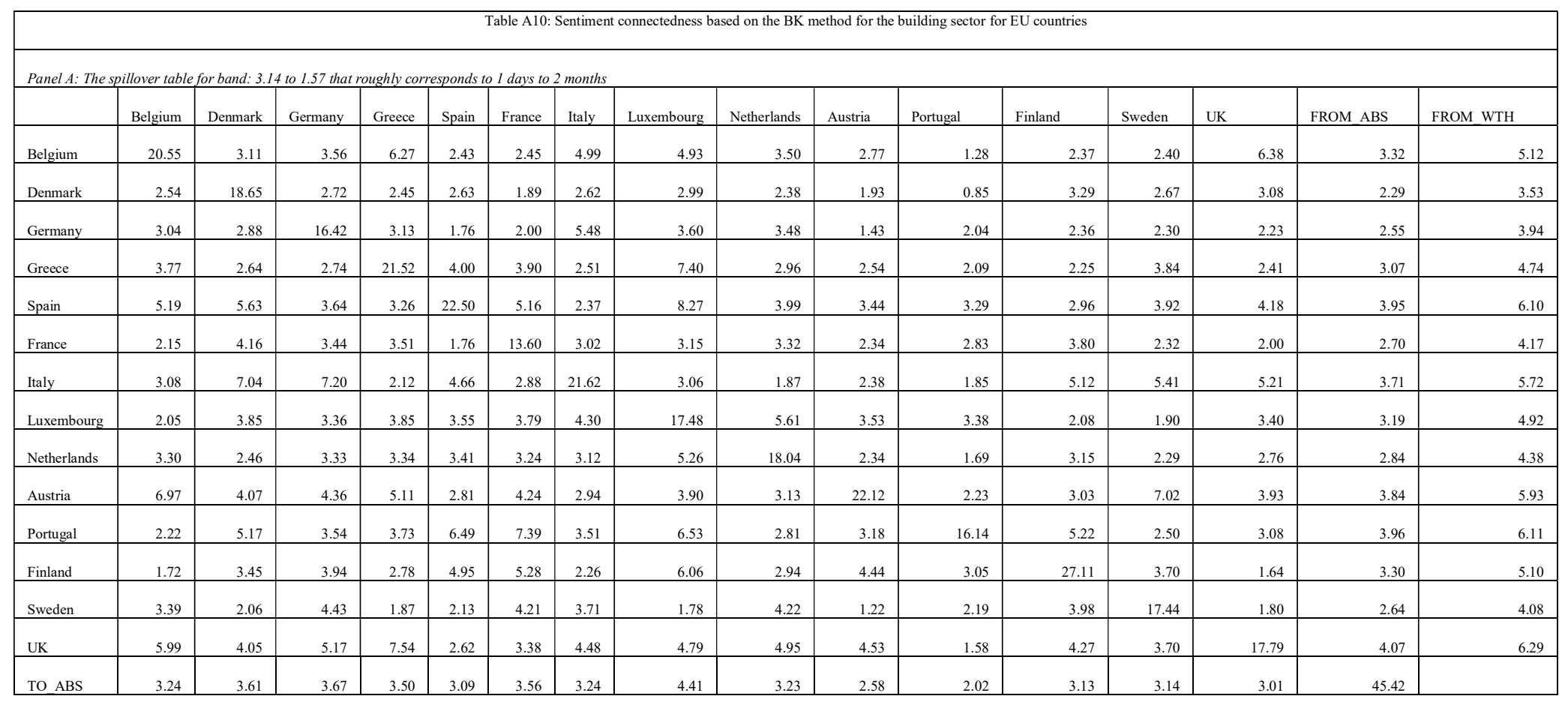




\begin{tabular}{|c|c|c|c|c|c|c|c|c|c|c|c|c|c|c|c|c|}
\hline TO_WTH & 5.01 & 5.58 & 5.67 & 5.40 & 4.76 & 5.49 & 5.00 & 6.81 & 4.98 & 3.98 & 3.12 & 4.84 & 4.85 & 4.64 & & 70.12 \\
\hline Net & -0.07 & 1.32 & 1.12 & 0.42 & -0.86 & 0.86 & -0.47 & 1.22 & 0.39 & -1.26 & -1.93 & -0.17 & 0.50 & -1.07 & & \\
\hline \multicolumn{17}{|c|}{ Panel B: The spillover table for band: 1.57 to 0.79 that roughly corresponds to 2 days to 4 months } \\
\hline Belgium & 2.91 & 0.47 & 0.64 & 0.42 & 0.66 & 1.73 & 1.26 & 1.60 & 1.47 & 0.45 & 0.97 & 0.86 & 1.21 & 0.97 & 0.91 & 4.81 \\
\hline Denmark & 0.52 & 6.71 & 1.44 & 2.00 & 1.54 & 4.38 & 1.15 & 1.28 & 1.10 & 1.09 & 0.81 & 0.90 & 1.04 & 1.75 & 1.36 & 7.20 \\
\hline Germany & 0.78 & 1.41 & 8.30 & 0.59 & 1.23 & 1.34 & 1.57 & 1.74 & 1.30 & 0.76 & 1.33 & 0.91 & 0.41 & 1.06 & 1.03 & 5.47 \\
\hline Greece & 1.45 & 1.10 & 1.55 & 4.68 & 1.02 & 0.80 & 1.77 & 1.82 & 0.71 & 1.11 & 2.11 & 0.91 & 0.37 & 3.04 & 1.27 & 6.73 \\
\hline Spain & 0.29 & 1.35 & 1.04 & 0.42 & 5.78 & 0.95 & 0.67 & 0.47 & 0.59 & 0.88 & 0.45 & 0.65 & 0.23 & 1.03 & 0.64 & 3.41 \\
\hline France & 0.39 & 0.48 & 0.46 & 0.50 & 0.49 & 4.88 & 0.61 & 0.48 & 0.54 & 0.32 & 0.41 & 0.45 & 0.53 & 0.56 & 0.44 & 2.35 \\
\hline Italy & 0.55 & 1.31 & 1.89 & 0.56 & 1.13 & 0.90 & 5.85 & 1.15 & 1.09 & 1.64 & 0.15 & 0.20 & 0.53 & 2.45 & 0.97 & 5.14 \\
\hline Luxembourg & 1.00 & 0.62 & 1.34 & 1.11 & 0.26 & 1.68 & 1.06 & 6.96 & 1.85 & 0.83 & 1.02 & 1.28 & 0.28 & 3.07 & 1.10 & 5.83 \\
\hline Netherlands & 0.84 & 2.49 & 0.87 & 0.59 & 0.55 & 1.53 & 0.79 & 1.22 & 6.22 & 1.19 & 1.35 & 0.72 & 0.56 & 2.81 & 1.11 & 5.87 \\
\hline Austria & 0.25 & 2.41 & 0.99 & 0.24 & 1.35 & 0.82 & 0.71 & 1.52 & 1.43 & 5.55 & 0.54 & 0.20 & 1.23 & 2.07 & 0.98 & 5.21 \\
\hline Portugal & 1.07 & 0.98 & 1.02 & 0.68 & 1.15 & 1.24 & 0.72 & 2.84 & 1.18 & 1.02 & 4.40 & 0.30 & 0.41 & 0.56 & 0.94 & 4.98 \\
\hline Finland & 0.54 & 2.00 & 0.65 & 0.72 & 0.69 & 1.60 & 0.49 & 1.34 & 1.66 & 1.33 & 0.79 & 2.91 & 0.83 & 0.83 & 0.96 & 5.10 \\
\hline Sweden & 0.61 & 0.82 & 1.23 & 0.71 & 0.66 & 1.32 & 1.07 & 0.56 & 3.34 & 0.44 & 0.81 & 0.45 & 3.91 & 1.97 & 1.00 & 5.30 \\
\hline UK & 0.75 & 0.92 & 0.64 & 0.47 & 0.39 & 1.21 & 0.38 & 1.15 & 1.31 & 0.52 & 0.56 & 1.27 & 0.11 & 7.29 & 0.69 & 3.67 \\
\hline TO_ABS & 0.65 & 1.17 & 0.98 & 0.64 & 0.79 & 1.39 & 0.88 & 1.23 & 1.25 & 0.83 & 0.81 & 0.65 & 0.55 & 1.58 & 13.40 & \\
\hline TO WTH & 3.43 & 6.20 & 5.21 & 3.41 & 4.21 & 7.39 & 4.65 & 6.50 & 6.65 & 4.39 & 4.28 & 3.44 & 2.93 & 8.39 & & 71.07 \\
\hline Net & -0.26 & -0.19 & -0.05 & -0.63 & 0.15 & 0.95 & -0.09 & 0.13 & 0.15 & -0.15 & -0.13 & -0.31 & -0.45 & 0.89 & & \\
\hline eel C: The & er table & $n d: 0$. & 0.39 that & hly col & ponds & days to & months & & & & & & & & & \\
\hline Belgium & 1.79 & 0.06 & 0.24 & 0.27 & 0.36 & 0.07 & 0.12 & 0.05 & 0.19 & 0.06 & 0.10 & 0.05 & 0.75 & 0.20 & 0.18 & 3.19 \\
\hline Denmark & 0.53 & 3.51 & 1.98 & 0.90 & 0.51 & 0.63 & 0.91 & 0.40 & 0.57 & 0.97 & 0.26 & 0.25 & 1.31 & 0.75 & 0.71 & 12.66 \\
\hline Germany & 0.52 & 0.15 & 3.71 & 0.54 & 0.18 & 0.06 & 0.16 & 0.08 & 0.44 & 0.08 & 0.12 & 0.12 & 0.28 & 0.17 & 0.21 & 3.70 \\
\hline Greece & 0.57 & 0.42 & 0.74 & 1.82 & 0.58 & 0.76 & 0.44 & 0.26 & 0.27 & 0.43 & 0.30 & 0.10 & 0.20 & 0.44 & 0.39 & 7.01 \\
\hline Spain & 0.22 & 0.17 & 0.19 & 0.17 & 1.21 & 0.10 & 0.02 & 0.44 & 0.25 & 0.25 & 0.22 & 0.24 & 0.23 & 0.10 & 0.19 & 3.30 \\
\hline
\end{tabular}




\begin{tabular}{|c|c|c|c|c|c|c|c|c|c|c|c|c|c|c|c|c|}
\hline France & 0.38 & 0.04 & 0.10 & 0.72 & 0.06 & 1.81 & 0.13 & 0.25 & 0.70 & 0.14 & 0.49 & 0.16 & 0.09 & 0.33 & 0.26 & 4.57 \\
\hline Italy & 0.10 & 0.05 & 0.59 & 0.31 & 0.17 & 0.02 & 1.24 & 0.36 & 0.23 & 0.49 & 0.14 & 0.25 & 0.28 & 0.21 & 0.23 & 4.09 \\
\hline Luxembourg & 0.21 & 0.78 & 0.12 & 0.32 & 0.27 & 0.51 & 0.13 & 3.88 & 0.55 & 0.20 & 0.49 & 0.20 & 0.35 & 0.34 & 0.32 & 5.68 \\
\hline Netherlands & 0.13 & 0.22 & 0.22 & 0.23 & 0.17 & 0.08 & 0.14 & 0.10 & 1.34 & 0.14 & 0.04 & 0.12 & 0.16 & 0.45 & 0.16 & 2.78 \\
\hline Austria & 0.08 & 0.16 & 0.19 & 0.11 & 0.19 & 0.19 & 0.05 & 0.34 & 0.26 & 0.94 & 0.14 & 0.15 & 0.09 & 0.08 & 0.15 & 2.58 \\
\hline Portugal & 0.06 & 0.13 & 0.17 & 0.13 & 0.10 & 0.07 & 0.12 & 0.75 & 0.29 & 0.07 & 0.61 & 0.10 & 0.10 & 0.09 & 0.15 & 2.75 \\
\hline Finland & 0.09 & 0.03 & 0.11 & 0.24 & 0.12 & 0.27 & 0.16 & 0.23 & 0.38 & 0.51 & 0.06 & 1.02 & 0.17 & 0.21 & 0.18 & 3.26 \\
\hline Sweden & 0.65 & 0.49 & 0.07 & 0.76 & 0.25 & 0.27 & 0.45 & 1.17 & 0.51 & 0.28 & 0.51 & 0.06 & 2.64 & 1.34 & 0.49 & 8.64 \\
\hline UK & 0.24 & 0.06 & 0.04 & 0.12 & 0.06 & 0.10 & 0.16 & 0.30 & 0.11 & 0.25 & 0.05 & 0.08 & 0.04 & 1.03 & 0.11 & 2.03 \\
\hline TO_ABS & 0.27 & 0.20 & 0.34 & 0.35 & 0.22 & 0.22 & 0.21 & 0.34 & 0.34 & 0.28 & 0.21 & 0.13 & 0.29 & 0.34 & 3.73 & \\
\hline TO_WTH & 4.82 & 3.52 & 6.05 & 6.15 & 3.85 & 3.98 & 3.80 & 6.00 & 6.01 & 4.92 & 3.70 & 2.39 & 5.12 & 5.97 & & 66.27 \\
\hline Net & 0.09 & -0.51 & 0.13 & -0.05 & 0.03 & -0.03 & -0.02 & 0.02 & 0.18 & 0.13 & 0.05 & -0.05 & -0.20 & 0.22 & & \\
\hline \multicolumn{17}{|c|}{ Panel D: The spillover table for band: 0.39 to 0.20 that roughly corresponds to 8 days to 16 months } \\
\hline Belgium & 0.60 & 0.04 & 0.07 & 0.11 & 0.34 & 0.18 & 0.11 & 0.02 & 0.06 & 0.19 & 0.07 & 0.06 & 0.14 & 0.15 & 0.11 & 3.60 \\
\hline Denmark & 0.32 & 0.42 & 0.07 & 0.16 & 0.17 & 0.33 & 0.03 & 0.05 & 0.28 & 0.21 & 0.09 & 0.03 & 0.38 & 0.31 & 0.17 & 5.66 \\
\hline Germany & 0.17 & 0.12 & 3.70 & 1.46 & 0.11 & 0.19 & 0.02 & 0.27 & 0.43 & 0.12 & 0.46 & 0.05 & 0.43 & 0.11 & 0.28 & 9.24 \\
\hline Greece & 0.18 & 0.11 & 0.37 & 0.68 & 0.07 & 0.09 & 0.17 & 0.03 & 0.05 & 0.09 & 0.08 & 0.01 & 0.52 & 0.10 & 0.13 & 4.37 \\
\hline Spain & 0.12 & 0.09 & 0.05 & 0.18 & 0.50 & 0.16 & 0.02 & 0.09 & 0.04 & 0.06 & 0.07 & 0.07 & 0.13 & 0.08 & 0.08 & 2.72 \\
\hline France & 0.68 & 0.02 & 0.02 & 0.94 & 0.25 & 1.66 & 0.07 & 0.27 & 0.72 & 0.25 & 0.37 & 0.04 & 0.30 & 1.01 & 0.35 & 11.52 \\
\hline Italy & 0.02 & 0.00 & 0.04 & 0.00 & 0.09 & 0.04 & 0.31 & 0.11 & 0.01 & 0.02 & 0.02 & 0.01 & 0.07 & 0.18 & 0.04 & 1.41 \\
\hline Luxembourg & 0.23 & 0.16 & 0.01 & 0.12 & 0.29 & 0.17 & 0.10 & 0.98 & 0.27 & 0.06 & 0.05 & 0.19 & 0.26 & 0.55 & 0.18 & 5.73 \\
\hline Netherlands & 0.09 & 0.04 & 0.05 & 0.16 & 0.20 & 0.03 & 0.05 & 0.10 & 1.03 & 0.26 & 0.11 & 0.01 & 0.31 & 0.57 & 0.14 & 4.62 \\
\hline Austria & 0.01 & 0.05 & 0.02 & 0.04 & 0.02 & 0.03 & 0.01 & 0.05 & 0.06 & 0.21 & 0.02 & 0.07 & 0.02 & 0.04 & 0.03 & 1.00 \\
\hline Portugal & 0.13 & 0.02 & 0.12 & 0.02 & 0.09 & 0.14 & 0.12 & 0.18 & 0.06 & 0.10 & 0.36 & 0.04 & 0.21 & 0.12 & 0.10 & 3.16 \\
\hline Finland & 0.14 & 0.13 & 0.16 & 0.44 & 0.08 & 0.31 & 0.08 & 0.05 & 0.06 & 0.16 & 0.04 & 0.37 & 0.07 & 0.47 & 0.16 & 5.15 \\
\hline Sweden & 0.17 & 0.01 & 0.13 & 0.20 & 0.07 & 0.49 & 0.21 & 0.21 & 0.14 & 0.08 & 0.09 & 0.02 & 2.32 & 0.95 & 0.20 & 6.46 \\
\hline
\end{tabular}




\begin{tabular}{|c|c|c|c|c|c|c|c|c|c|c|c|c|c|c|c|c|}
\hline UK & 0.08 & 0.02 & 0.03 & 0.11 & 0.10 & 0.09 & 0.12 & 0.10 & 0.10 & 0.30 & 0.02 & 0.04 & 0.13 & 0.76 & 0.09 & 2.88 \\
\hline TO_ABS & 0.17 & 0.06 & 0.08 & 0.28 & 0.13 & 0.16 & 0.08 & 0.11 & 0.16 & 0.14 & 0.11 & 0.05 & 0.21 & 0.33 & 2.07 & \\
\hline TO_WTH & 5.47 & 1.89 & 2.64 & 9.21 & 4.41 & 5.27 & 2.59 & 3.62 & 5.34 & 4.42 & 3.44 & 1.48 & 6.91 & 10.85 & & 67.52 \\
\hline Net & 0.06 & -0.12 & -0.20 & 0.15 & 0.05 & -0.19 & 0.04 & -0.06 & 0.02 & 0.10 & 0.01 & -0.11 & 0.01 & 0.24 & & \\
\hline \multicolumn{17}{|c|}{ Panel E: The spillover table for band: 0.20 to 0.00 that roughly corresponds to more than 16 months } \\
\hline Belgium & 1.41 & 0.23 & 0.87 & 2.28 & 3.11 & 0.71 & 0.29 & 0.16 & 0.38 & 0.14 & 0.23 & 0.14 & 0.40 & 0.60 & 0.68 & 8.86 \\
\hline Denmark & 0.36 & 1.81 & 0.49 & 1.44 & 0.83 & 0.42 & 0.28 & 0.10 & 0.15 & 0.10 & 0.18 & 0.04 & 0.18 & 0.91 & 0.39 & 5.09 \\
\hline Germany & 0.39 & 0.05 & 4.71 & 2.42 & 0.73 & 0.21 & 0.45 & 0.12 & 0.10 & 0.22 & 0.15 & 0.09 & 0.97 & 0.22 & 0.44 & 5.69 \\
\hline Greece & 0.24 & 0.02 & 0.45 & 1.26 & 0.09 & 0.05 & 0.07 & 0.05 & 0.03 & 0.14 & 0.07 & 0.05 & 0.53 & 0.07 & 0.13 & 1.72 \\
\hline Spain & 0.05 & 0.11 & 0.08 & 0.14 & 1.05 & 0.04 & 0.09 & 0.04 & 0.06 & 0.11 & 0.08 & 0.03 & 0.03 & 0.04 & 0.06 & 0.82 \\
\hline France & 2.04 & 1.38 & 2.38 & 4.61 & 5.85 & 3.93 & 1.19 & 0.43 & 0.51 & 0.25 & 0.43 & 0.25 & 0.56 & 1.71 & 1.54 & 20.05 \\
\hline Italy & 0.17 & 0.05 & 0.13 & 0.10 & 0.26 & 0.16 & 0.34 & 0.02 & 0.02 & 0.06 & 0.02 & 0.03 & 0.08 & 0.27 & 0.10 & 1.28 \\
\hline Luxembourg & 0.46 & 0.14 & 0.11 & 0.29 & 0.65 & 0.23 & 0.03 & 0.45 & 0.33 & 0.11 & 0.22 & 0.04 & 0.33 & 0.34 & 0.23 & 3.05 \\
\hline Netherlands & 0.36 & 0.76 & 1.26 & 1.59 & 4.16 & 0.16 & 0.14 & 0.23 & 1.53 & 0.62 & 1.32 & 0.11 & 0.70 & 1.06 & 0.89 & 11.60 \\
\hline Austria & 0.05 & 0.05 & 0.16 & 0.23 & 0.16 & 0.08 & 0.15 & 0.03 & 0.10 & 0.12 & 0.05 & 0.01 & 0.03 & 0.03 & 0.08 & 1.04 \\
\hline Portugal & 0.29 & 0.50 & 0.31 & 0.24 & 1.35 & 0.13 & 0.52 & 0.13 & 0.80 & 0.15 & 1.52 & 0.23 & 0.19 & 0.06 & 0.35 & 4.57 \\
\hline Finland & 0.28 & 0.26 & 0.37 & 0.71 & 0.47 & 0.37 & 0.24 & 0.05 & 0.04 & 0.07 & 0.16 & 0.39 & 0.08 & 0.66 & 0.27 & 3.49 \\
\hline Sweden & 0.96 & 0.65 & 0.74 & 2.03 & 2.37 & 0.66 & 0.24 & 0.08 & 0.46 & 0.41 & 0.67 & 0.04 & 2.55 & 1.28 & 0.76 & 9.85 \\
\hline $\mathrm{UK}$ & 0.05 & 0.37 & 0.33 & 0.03 & 0.33 & 0.10 & 0.10 & 0.02 & 0.06 & 0.40 & 0.06 & 0.03 & 0.28 & 1.39 & 0.16 & 2.02 \\
\hline TO_ABS & 0.41 & 0.33 & 0.55 & 1.15 & 1.45 & 0.24 & 0.27 & 0.10 & 0.22 & 0.20 & 0.26 & 0.08 & 0.31 & 0.52 & 6.08 & \\
\hline TO_wTH & 5.30 & 4.25 & 7.14 & 14.98 & 18.93 & 3.08 & 3.52 & 1.36 & 2.84 & 2.59 & 3.38 & 1.00 & 4.04 & 6.73 & & 79.13 \\
\hline Net & -0.27 & -0.06 & 0.11 & 1.02 & 1.39 & -1.30 & 0.17 & -0.13 & -0.67 & 0.12 & -0.09 & -0.19 & -0.45 & 0.36 & & \\
\hline
\end{tabular}

